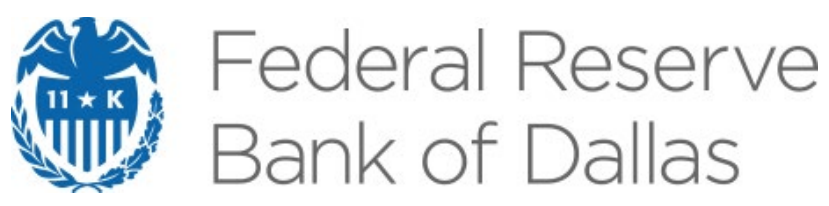

\title{
Countercyclical Fluctuations in Uncertainty are Endogenous
}

Joshua Bernstein, Michael Plante, Alexander W. Richter and Nathaniel A. Throckmorton

Research Department https://doi.org/10.24149/wp2109

Working papers from the Federal Reserve Bank of Dallas are preliminary drafts circulated for professional comment. The views in this paper are those of the authors and do not necessarily reflect the views of the Federal Reserve Bank of Dallas or the Federal Reserve System. Any errors or omissions are the responsibility of the authors. 


\title{
Countercyclical Fluctuations in Uncertainty are Endogenous*
}

\author{
Joshua Bernstein ${ }^{\dagger}$, Michael Plante ${ }^{\ddagger}$, Alexander W. Richter ${ }^{\S}$ and Nathaniel A. \\ Throckmorton ${ }^{ \pm}$
}

July 1,2021

\begin{abstract}
This paper uses a battery of calibrated and estimated structural models to determine the causal drivers of the negative correlation between output and aggregate uncertainty. We find the transmission of uncertainty shocks to output is weak, while aggregate uncertainty endogenously responds to first moment shocks in the presence of labor market search frictions. This indicates that countercyclical movements in aggregate uncertainty are endogenous responses to changes in output, rather than exogenous impulses. A vector autoregression on simulated data shows recursive identification techniques do not robustly identify structural uncertainty shocks.
\end{abstract}

Keywords: Uncertainty Shocks; Endogenous Uncertainty; Variance Decomposition; Nonlinear

JEL Classifications: C13; D81; E32; E37; J64

\footnotetext{
*We thank Jarod Coulter for excellent research assistance. This work was supported by computational resources provided by the BigTex High Performance Computing Group at the Federal Reserve Bank of Dallas. The views expressed in this paper are our own and do not necessarily reflect the views of the Federal Reserve Bank of Dallas or the Federal Reserve System.

†Joshua Bernstein, Department of Economics, Indiana University, 100 S. Woodlawn, Bloomington, IN 47405 (imbernst@iu.edu)

¥Michael Plante, Federal Reserve Bank of Dallas, 2200 N. Pearl Street, Dallas, TX 75201 (michael.plante@dal.frb.org).

§Alexander W. Richter, Federal Reserve Bank of Dallas, 2200 N. Pearl Street, Dallas, TX 75201 (alex.richter@dal.frb.org). ${ }^{ \pm}$Nathaniel A. Throckmorton, Department of Economics, William \& Mary, P.O. Box 8795, Williamsburg, VA 23187 (nat@wm.edu).
} 


\section{INTRODUCTION}

Countercyclical variation in aggregate uncertainty - conditional forecast error volatilities of macroeconomic aggregates-is a well-documented feature of U.S. data. Whether the negative correlation between real activity and its uncertainty is driven by the transmission of uncertainty shocks to output or the transmission of output shocks to uncertainty remains an open question. This paper answers this question using a battery of structural models driven by level and uncertainty shocks to technology. We find that fluctuations in output can cause fluctuations in uncertainty, while exogenous changes in uncertainty never cause significant fluctuations in output. This indicates that countercyclical movements in aggregate uncertainty are endogenous responses to fluctuations in real activity and that exogenous uncertainty shocks play virtually no role in driving the business cycle.

We discipline our quantitative analysis by targeting the real uncertainty series constructed by Ludvigson et al. (2021), which captures the common component of uncertainty across 73 measures of real activity in the data. This series is particularly useful because it strips out the predictable variation in macroeconomic aggregates, leaving only the variance of the unforecastable component (i.e., uncertainty), and it is straightforward to compute an equivalent statistic in structural models. We document that it has a small standard deviation and a strong negative correlation with output.

To guide our analysis, we first perform a simple calibration exercise using three commonly used models: the real business cycle (RBC) model, the New Keynesian (NK) model, and the DiamondMortensen-Pissarides (DMP) search and matching model. In each model, we posit that business cycles are driven by two exogenous shock processes that generate variation in the first and second moments of technology. We calibrate these stochastic processes to target the standard deviations of aggregate uncertainty and output in the data and set the remaining parameters to typical values.

Two clear results emerge from our calibration exercise. First, uncertainty shocks play virtually no role in explaining the business cycle fluctuations in output and are therefore uncorrelated with output. Second, in the DMP model, first moment shocks cause aggregate uncertainty to endogenously increase when output falls, creating a strong negative correlation in line with the data. In sharp contrast, the RBC and NK models fail to generate any correlation between output and uncertainty because neither of these models generate endogenous fluctuations in aggregate uncertainty.

The transmission of first moment shocks to aggregate uncertainty in the DMP model operates through the law of motion for unemployment. A negative technology shock decreases output and increases unemployment. A larger amount of unemployed workers generates more variability in future outflows from unemployment and therefore greater uncertainty about future unemployment and output. We find that this channel explains about half of the uncertainty fluctuations in the data.

Our calibration exercise leads to smaller volatility shocks than some papers in the literature. To examine whether larger uncertainty shocks would overturn our findings, we consider an alternative 
calibration that sets the volatility shock standard deviation to a similar value as Leduc and Liu (2016) and Fernández-Villaverde and Guerrón-Quintana (2020). In this case, each model grossly overstates the variation in aggregate uncertainty and misses the correlation with output. Furthermore, while uncertainty shocks appear to drive about $40 \%$ of the variation of output under this calibration, we show this effect is due to a mechanical interaction between first and second moment shocks. Large second moment shocks generate larger changes in the size of first moment shocks, which increase the volatility of output. The transmission of uncertainty shocks to output is less affected by channels such as precautionary savings or real option effects emphasized in the literature.

Having established the DMP model as a strong candidate to explain the countercyclical variation of aggregate uncertainty, we ask how well it can jointly explain the cyclical variation in first and second moments of real activity. We estimate the nonlinear model using a simulated method of moments and find it closely matches a range of business cycle moments, including the standard deviation, autocorrelation, and cyclicality of aggregate uncertainty. These results show that the model provides a credible description of both real activity and uncertainty over the business cycle. Importantly, it generates almost the same variance decompositions as our calibrated DMP model.

We use our estimated model to revisit the reduced-form evidence for the transmission of uncertainty shocks to output. A prominent literature has used recursive identification schemes in structural vector autoregressions to identify the causal effect of uncertainty shocks on output and applied this evidence to discipline structural models in which causality runs from uncertainty to output (e.g. Basu and Bundick, 2017; Leduc and Liu, 2016; Oh, 2020). Applying these estimation techniques to simulated data from our model generates responses of output to uncertainty shocks that are similar to the empirical evidence, even though we know the true structural uncertainty shocks have almost zero impact on output. Therefore, a recursive identification scheme does not necessarily pick up the true transmission mechanism from uncertainty to output. This finding is consistent with Ludvigson et al. (2021), who develop a more sophisticated identification strategy and show it is inconsistent with recursive methods. They also find the causal effect of real uncertainty shocks on output is small, while real uncertainty responds to output shocks, consistent with our DMP model.

Related Literature This paper's main contribution is to decompose the negative correlation between uncertainty and real activity into its causal drivers. Our emphasis on the DMP model has precedent in the literature, though our main findings differ substantially. In an influential paper, Leduc and Liu (2016) show that unemployment increases in response to heightened uncertainty, as measured by the University of Michigan Survey of Consumers. ${ }^{1}$ More recently, Cacciatore and Ravenna (2021) introduce asymmetric wage dynamics into a DMP model and show that they can amplify the response of unemployment to uncertainty shocks, especially in deep recessions. How-

\footnotetext{
${ }^{1}$ See Den Haan et al. (2020) for a discussion of the DMP model that clarifies the results in Leduc and Liu (2016).
} 
ever, the overall effects of uncertainty shocks remain small elsewhere in the ergodic distribution, so these shocks cannot be the primary source of the negative correlation in the data. Relative to these papers, we use the DMP model to instead argue that the correlation is explained by reverse causality, from output to uncertainty. The fact that the textbook DMP model generates endogenous uncertainty responses to first moment shocks builds on earlier work by Bernstein et al. (2021) who show that the law of motion for unemployment is a powerful source of endogenous uncertainty, as well as Cacciatore and Ravenna (2021) in the context of asymmetric wage adjustment. ${ }^{2}$ Crucially, neither of these papers attempt to decompose the negative correlation into its causal components.

Our consideration of both directions of causality distinguishes us from a work focused on causality from uncertainty shocks to output. Several papers argue that uncertainty shocks can exacerbate recessions. ${ }^{3}$ Born and Pfeifer $(2014,2021)$ argue that such shocks are unlikely to play a major role in driving the business cycle due to their small size and weak transmission mechanisms. Our calibration exercise complements this finding by using data on uncertainty to reach a similar conclusion in three textbook macro models. We then examine reverse causality from output to uncertainty and show that it successfully explains the negative correlation in a textbook DMP model.

To decompose the variance of output and uncertainty into its structural components, we follow Isakin and Ngo (2020) and use a Total Variance Decomposition. This method takes into account nonlinearities and multiplicative interaction effects that occur between level and volatility shocks. Linear Forecast Error Variance Decompositions (FEVD) miss both of those effects, while generalized FEVDs based on generalized impulse response functions (Lanne and Nyberg, 2016) miss the multiplicative interaction effects. To the best of our knowledge, we are the first to use this method to conduct variance decompositions in an estimated macro model. We show it is crucial to account for interaction effects in order to accurately quantify the contributions of level and volatility shocks.

Finally, we note that our analysis focuses on the component of aggregate uncertainty linked to real activity. As such, we do not claim to explain the relationships between real activity and uncertainty in financial markets (e.g. the financial uncertainty index in Ludvigson et al. (2021), which is based on 148 financial time series) or uncertainty at the micro level (e.g., dispersion in firm productivity). Influential examples of papers in these areas include Bloom (2007), Bachmann and Bayer (2013), Gilchrist et al. (2014), Christiano et al. (2014), Chugh (2016), Bloom et al. (2018),

\footnotetext{
${ }^{2}$ Our mechanism complements papers that focus on other sources of time-varying endogenous uncertainty (Arellano et al., 2019; Benhabib et al., 2016; Brunnermeier and Sannikov, 2014; Fajgelbaum et al., 2017; Ilut et al., 2018; Mendoza, 2010; Plante et al., 2018; Saijo, 2017; Straub and Ulbricht, 2015; Van Nieuwerburgh and Veldkamp, 2006).

${ }^{3}$ Following Justiniano and Primiceri (2008), a large literature has studied the effects of uncertainty shocks on the business cycle. Fernández-Villaverde et al. (2011) study how volatility shocks to the real interest rate affect fluctuations in emerging market economies, Mumtaz and Zanetti (2013) show that uncertainty shocks in the monetary policy rule affect its transmission mechanism, Fernández-Villaverde et al. (2015) show that heightened fiscal uncertainty can exacerbate recessionary episodes, Leduc and Liu (2016) study how uncertainty shocks to technology affect unemployment dynamics, and Basu and Bundick (2017) use preference uncertainty shocks to capture the interaction between real activity and financial uncertainty. See Fernández-Villaverde and Guerrón-Quintana (2020) for a review of the literature.
} 
and Sedláček (2020). Extending our methods to these important topics is left for future research.

The paper proceeds as follows. Section 2 introduces the empirical measure of aggregate uncertainty and its key statistical properties. Section 3 describes our models. Section 4 shows the results from our calibration exercise, and Section 5 provides our estimation results. Section 6 concludes.

\section{Measuring Aggregate UnCertainty}

To comprehensively assess how well theoretical macro models can account for the interaction of uncertainty with real activity, we first need an empirical measure of uncertainty. To this end, we follow the methodology of Jurado et al. (2015) and Ludvigson et al. (2021), who define the uncertainty of an outcome $y_{j, t}$ as the period- $t$ conditional volatility of its $h$-period ahead forecast error,

$$
\mathcal{U}_{j, t}(h)=\sqrt{E_{t}\left[\left(y_{j, t+h}-E_{t}\left[y_{j, t+h}\right]\right)^{2}\right]} .
$$

Given a vector of outcomes $Y_{t}=\left[y_{1, t}, y_{2, t}, \ldots, y_{N, t}\right]^{\prime}$, aggregate uncertainty is then defined as

$$
\mathcal{U}_{t}(h)=\frac{1}{N} \sum_{j=1}^{N} \mathcal{U}_{j, t}(h),
$$

which is the cross-sectional average of the individual uncertainty measures. As Jurado et al. (2015) note, this definition has three useful features. ${ }^{4}$ First, the conditional volatility calculation strips out the predictable variation in each outcome using the conditional expectation, leaving only the variance of the unforecastable component. Second, the aggregation step ensures that aggregate uncertainty measures the common component of uncertainty across a large set of data, rather than idiosyncratic fluctuations in any one time series. Third, this definition of uncertainty is easily computable in most models, which allows for a transparent comparison between the model and data.

We focus on the real uncertainty series introduced by Ludvigson et al. (2021). ${ }^{5}$ To obtain this measure, they estimate a factor-augmented vector autoregression (FAVAR) with stochastic volatility using monthly data on over 280 macro and financial time series. All series are made stationary and standardized before estimating. The FAVAR produces estimates of $E_{t}\left[y_{j, t+h}\right]$ for each outcome given a forecast horizon, $h$. The uncertainty of each individual series, $\mathcal{U}_{j, t}(h)$, is constructed using a stochastic volatility model of the forecast errors of each series. The real uncertainty measure is the mean of $\mathcal{U}_{j, t}(h)$ across 73 monthly measures of real activity. Using a quarterly horizon $(h=3)$, we then average across months within each quarter to produce a quarterly real uncertainty series.

\footnotetext{
${ }^{4}$ The literature has also used other measures of uncertainty, such as the VIX, forecast dispersion, and the policy uncertainty index of Baker et al. (2016). However, as Jurado et al. (2015) point out, there is no guarantee that these proxies capture uncertainty. The VIX can fluctuate for reasons that are unrelated to changes in uncertainty, such as changes in risk aversion or firm leverage. Disagreement among forecasters could stem from a number of factors and may not reflect fluctuations in uncertainty, and the policy uncertainty index is more narrowly focused than we require.

${ }^{5}$ Ludvigson et al. (2021) show that real and financial uncertainty have different causal effects on output in the data, so it is important to distinguish between them. We leave a joint analysis of the two types of uncertainty for future work.
} 


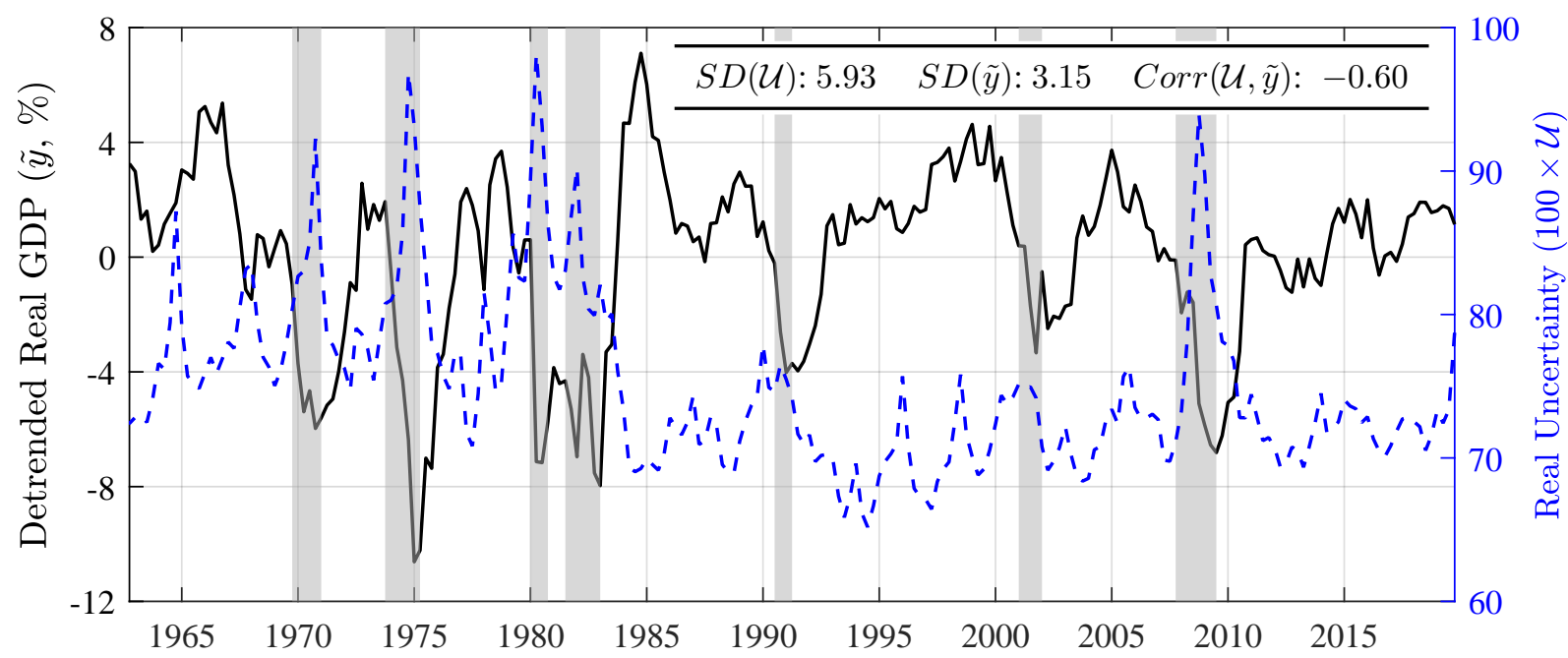

Figure 1: Per capita real GDP growth and real uncertainty over a 1-quarter horizon.

The Cyclical Behavior of Uncertainty Figure 1 plots our quarterly real uncertainty series (righthand axis) and the log growth rate of U.S. real GDP (left-hand axis). Similar to the monthly series in Jurado et al. (2015) and Ludvigson et al. (2021), the quarterly real uncertainty series is countercyclical, rising during recessions. These patterns are summarized by several useful statistics that inform the calibration of our theoretical models and are reported at the top of the figure - the standard deviations of real uncertainty and detrended output, and their correlation. Given the standardization of the data series used to construct $\mathcal{U}$, the standard deviation of uncertainty can be loosely interpreted as $5.93 \%$ of the standard deviation of output growth. Therefore, the fluctuations in uncertainty are considerably smaller than macroeconomic aggregates. The countercyclical nature of those fluctuations is captured by the strong -0.60 correlation between real uncertainty and output.

Alternative Uncertainty Measures There is no unique way to compute an aggregate uncertainty index in the data. An alternative to the real uncertainty index is to use the macro uncertainty series introduced in Jurado et al. (2015) and Ludvigson et al. (2021), which is a broader measure of uncertainty based on 134 real and financial variables. We denote this series by $\mathcal{U}_{m}$. For both of these indexes we apply quarterly averages to the monthly observations. We also produce quarterly series by directly estimating the FAVAR model with quarterly data. We denote these series by $\mathcal{U}^{q}$ and $\mathcal{U}_{m}^{q}$.

Table 1 reports the standard deviations, correlations, and cyclicality of our baseline and alternative uncertainty measures. We find the method of time aggregation and set of included time series has little effect on our statistics of interest. While the uncertainty series based on quarterly data and a larger set of time series are more volatile than our baseline uncertainty series, the standard deviations remain small-loosely speaking, no more than $11 \%$ of output volatility. Furthermore, all four uncertainty series are highly correlated with each other and exhibit nearly identical correlations with detrended output. This shows all of the series contain similar information about uncertainty. 


\begin{tabular}{lcllll}
\hline Std. Deviation & Value & Correlation & Value & Cyclicality & Value \\
\hline$S D(\mathcal{U})$ & 5.93 & $\operatorname{Corr}\left(\mathcal{U}_{,} \mathcal{U}^{q}\right)$ & 0.86 & $\operatorname{Corr}(\mathcal{U}, \tilde{y})$ & -0.60 \\
$S D\left(\mathcal{U}^{q}\right)$ & 7.53 & $\operatorname{Corr}\left(\mathcal{U}_{m}, \mathcal{U}_{m}^{q}\right)$ & 0.93 & $\operatorname{Corr}\left(\mathcal{U}_{m}, \tilde{y}\right)$ & -0.57 \\
$S D\left(\mathcal{U}_{m}\right)$ & 9.94 & $\operatorname{Corr}\left(\mathcal{U}_{\mathcal{U}_{m}}\right)$ & 0.75 & $\operatorname{Corr}\left(\mathcal{U}^{q}, \tilde{y}\right)$ & -0.59 \\
$S D\left(\mathcal{U}_{m}^{q}\right)$ & 10.68 & $\operatorname{Corr}\left(\mathcal{U}^{q}, \mathcal{U}_{m}^{q}\right)$ & 0.81 & $\operatorname{Corr}\left(\mathcal{U}_{m}^{q}, \tilde{y}\right)$ & -0.62 \\
\hline
\end{tabular}

Table 1: Alternative uncertainty moments. The standard deviations are percents and $\tilde{y}$ is detrended output. $\mathcal{U}$ is from Ludvigson et al. (2021) and $\mathcal{U}_{m}$ is from Jurado et al. (2015). Both series are estimated on monthly data and then aggregated to quarterly. The $q$ superscript refers to quarterly aggregation prior to estimation.

\section{Models And Decomposition Methods}

To understand how uncertainty interacts with real activity, we use textbook versions of the real business cycle (RBC), New Keynesian (NK), and Diamond-Mortensen-Pissarides (DMP) models.

Each model is driven by two exogenous processes. The first is technology (TFP), which follows

$$
\ln a_{t}=\left(1-\rho_{a}\right) \ln \bar{a}+\rho_{a} \ln a_{t-1}+\sigma_{a, t} \varepsilon_{a, t}, 0 \leq \rho_{a}<1, \varepsilon_{a, t} \sim \mathbb{N}(0,1) .
$$

The second driving force determines the volatility of TFP, which follows an independent process

$$
\ln \sigma_{a, t}=\left(1-\rho_{s v}\right) \ln \bar{\sigma}_{a}+\rho_{s v} \ln \sigma_{a, t-1}+\sigma_{s v} \varepsilon_{s v, t}, 0 \leq \rho_{s v}<1, \varepsilon_{s v, t} \sim \mathbb{N}(0,1) .
$$

Therefore, TFP is subject to stochastic volatility (uncertainty) shocks, $\varepsilon_{s v, t}$, that exogenously determine the time-variation in the standard deviation, $\sigma_{a, t}$, of first moment shocks, $\varepsilon_{a, t}$. It is important to specify the TFP process in natural logarithms. Since we will ultimately compute uncertainty moments for unit-less model quantities such as output growth, specifying TFP in logs ensures that we do not introduce exogenous curvature into the output growth process, which will be linear in $\ln a_{t}$.

3.1 Real Business Cycle Model A representative household chooses $\left\{c_{t}, n_{t}, k_{t}\right\}_{t=0}^{\infty}$ to maximize expected lifetime utility, $E_{0} \sum_{t=0}^{\infty} \beta^{t}\left[\ln c_{t}-\vartheta \frac{n_{t}^{1+\gamma}}{1+\gamma}\right]$, where $c_{t}$ is consumption, $n_{t}$ is labor hours, $k_{t}$ is capital, $\beta$ is the discount factor, $\vartheta$ determines steady-state labor hours, $1 / \gamma$ is the Frisch elasticity of labor supply, and $E_{0}$ is an expectation operator conditional on information in period 0. The household's choices are constrained by $c_{t}+i_{t}=w_{t} n_{t}+r_{t}^{k} k_{t-1}$ and the capital law of motion,

$$
k_{t}=(1-\delta) k_{t-1}+i_{t}
$$

where $i$ is investment, $w_{t}$ is the wage rate, and $r_{t}^{k}$ is the rental rate on capital. Optimality implies

$$
\begin{gathered}
w_{t}=\vartheta n_{t}^{\gamma} c_{t}, \\
1=E_{t}\left[x_{t+1}\left(r_{t+1}^{k}+1-\delta\right)\right],
\end{gathered}
$$


where $x_{t+1} \equiv \beta\left(c_{t} / c_{t+1}\right)$. The representative firm produces output with the following technology,

$$
y_{t}=a_{t} k_{t-1}^{\alpha} n_{t}^{1-\alpha}
$$

where $\alpha$ is the capital share of income. The firm chooses $\left\{n_{t}, k_{t-1}\right\}$ to maximize current profits, $y_{t}-w_{t} n_{t}-r_{t}^{k} k_{t-1}$, subject to the production function. The two optimality conditions are given by

$$
\begin{gathered}
w_{t}=(1-\alpha) y_{t} / n_{t}, \\
r_{t}^{k}=\alpha y_{t} / k_{t-1} .
\end{gathered}
$$

The aggregate resource constraint is given by

$$
c_{t}+i_{t}=y_{t}
$$

Equilibrium consists of quantities $\left\{y_{t}, k_{t}, c_{t}, n_{t}, i_{t}\right\}_{t=0}^{\infty}$, prices $\left\{w_{t}, r_{t}^{k}\right\}_{t=0}^{\infty}$, and exogenous variables $\left\{a_{t}, \sigma_{a, t}\right\}_{t=0}^{\infty}$ that satisfy (1)-(9), given the initial state $\left\{k_{-1}, a_{-1}, \sigma_{a,-1}\right\}$ and shocks $\left\{\varepsilon_{a, t}, \varepsilon_{\sigma_{a}, t}\right\}_{t=1}^{\infty}$.

3.2 New Keynesian Model The production sector now consists of a continuum of monopolistically competitive intermediate firms and a representative final good firm. Intermediate firm $f \in[0,1]$ produces a differentiated good, $y_{f, t}=a_{t} k_{f, t-1}^{\alpha} n_{f, t}^{1-\alpha}$, where $n_{f}$ and $k_{f}$ are the labor and capital inputs used by firm $f$. The final goods firm purchases output from each intermediate firm to produce a final good, $y_{t} \equiv\left[\int_{0}^{1} y_{f, t}^{(\theta-1) / \theta} d f\right]^{\theta /(\theta-1)}$, where $\theta>1$ is the elasticity of substitution.

Profit maximization by the final good firm determines the demand for intermediate good $f$, $y_{f, t}=\left(p_{f, t} / p_{t}\right)^{-\theta} y_{t}$, where $p_{t}=\left[\int_{0}^{1} p_{f, t}^{1-\theta} d f\right]^{1 /(1-\theta)}$ is the price level. Following Rotemberg (1982), intermediate firms pay a price adjustment cost, $\Lambda_{f, t}^{p} \equiv \varphi\left(p_{f, t} /\left(\bar{\pi} p_{f, t-1}\right)-1\right)^{2} y_{t} / 2$, where $\varphi>0$ scales the cost and $\bar{\pi}$ is the steady-state inflation rate. Given this cost, the value of firm $f$ satisfies

$$
V_{f, t}=\max _{n_{f, t}, k_{f, t-1}, p_{f, t}} p_{f, t} y_{f, t} / p_{t}-w_{t} n_{f, t}-r_{t}^{k} k_{f, t-1}-\Lambda_{f, t}^{p}+E_{t}\left[x_{t+1} V_{f, t+1}\right]
$$

subject to $y_{f, t}=a_{t} k_{f, t-1}^{\alpha} n_{f, t}^{1-\alpha}$ and $y_{f, t}=\left(p_{f, t} / p_{t}\right)^{-\theta} y_{t}$. In a symmetric equilibrium where $p_{f, t}=$ $p_{t}$, optimality implies the input demand schedules and New Keynesian Phillips curve are given by

$$
\begin{gathered}
w_{t}=(1-\alpha) m c_{t} y_{t} / n_{t}, \\
r_{t}^{k}=\alpha m c_{t} y_{t} / k_{t-1}, \\
\varphi\left(\pi_{t} / \bar{\pi}-1\right)\left(\pi_{t} / \bar{\pi}\right)=1-\theta+\theta m c_{t}+\beta \varphi E_{t}\left[\left(c_{t} / c_{t+1}\right)\left(\pi_{t+1} / \bar{\pi}-1\right)\left(\pi_{t+1} / \bar{\pi}\right) y_{t+1} / y_{t}\right],
\end{gathered}
$$

where $\pi_{t}=p_{t} / p_{t-1}$ is the gross inflation rate. If $\varphi=0$, then the real marginal cost of producing a unit of output, $m c_{t}$, equals $(\theta-1) / \theta$, which is the inverse of the markup of price over marginal cost. 
In addition to capital, the household has access to a nominal bond, so the budget constraint is

$$
c_{t}+i_{t}+b_{t}=r_{t}^{k} k_{t-1}+r_{t-1} b_{t-1} / \pi_{t}+d_{t}
$$

where $r_{t}$ is the gross nominal interest rate and $d_{t}$ is firm dividends. Optimality implies (4), (5), and

$$
1=E_{t}\left[x_{t+1}\left(r_{t} / \pi_{t+1}\right)\right]
$$

The central bank sets the gross nominal interest rate according to a typical Taylor rule given by

$$
r_{t}=\bar{r}\left(\pi_{t} / \bar{\pi}\right)^{\phi_{\pi}}
$$

where $\bar{r}$ is the nominal interest rate target and $\phi_{\pi}$ governs the strength of the response to inflation.

Equilibrium includes quantities $\left\{y_{t}, k_{t}, c_{t}, n_{t}, i_{t}\right\}_{t=0}^{\infty}$, prices $\left\{w_{t}, r_{t}^{k}, r_{t}, \pi_{t}, m c_{t}\right\}_{t=0}^{\infty}$, and exogenous variables $\left\{a_{t}, \sigma_{a, t}\right\}_{t=0}^{\infty}$ that satisfy (1)-(6) and (9)-(14), given the same initial state and shocks.

3.3 SeArch And Matching Model The representative household is populated by a unit mass of workers. ${ }^{6}$ Some workers in the household are unable to find jobs due to matching frictions. Entering period $t$, there are $n_{t-1}$ employed workers and $u_{t-1}=1-n_{t-1}$ unemployed workers. Within the period, $\bar{s}$ employed workers exogenously lose their jobs. These workers search for new jobs within the same period as their job loss. However, they will have less time to search for new jobs in period $t$ than those who became unemployed in a previous period. Let $\chi \in[0,1]$ denote the fraction of a period that newly separated workers spend searching for work in the same period as their job loss. Then the total number of unemployed searching workers in period $t$ is given by

$$
u_{t}^{s}=u_{t-1}+\chi \bar{s} n_{t-1} .
$$

The matching process is described by the following Cobb-Douglas function,

$$
\mathcal{M}\left(u_{t}^{s}, v_{t}\right)=\xi\left(u_{t}^{s}\right)^{\phi} v_{t}^{1-\phi}
$$

where $\xi>0$ is matching efficiency and $\phi \in(0,1)$ is the elasticity of matches with respect to unemployed searching. The number of matches, the job finding rate, and the job filling rate are given by

$$
\begin{gathered}
m_{t}=\min \left\{\mathcal{M}\left(u_{t}^{s}, v_{t}\right), u_{t}^{s}, v_{t}\right\}, \\
f_{t}=m_{t} / u_{t}^{s}, \\
q_{t}=m_{t} / v_{t} .
\end{gathered}
$$

\footnotetext{
${ }^{6}$ Following Merz (1995), Andolfatto (1996), and Den Haan et al. (2000) this approach assumes perfect consumption insurance across employed and unemployed workers and lets us compare outcomes to the RBC and NK models.
} 
Following Blanchard and Galí (2010), we assume newly matched workers begin employment in the same period they are matched with a firm. Hence, aggregate employment evolves according to

$$
n_{t}=(1-\bar{s}) n_{t-1}+m_{t}
$$

The unemployment rate $u_{t}$ includes anyone who is not employed in period $t$, so it is given by

$$
u_{t} \equiv u_{t}^{s}-m_{t}=1-n_{t}
$$

The representative household solves

subject to (3) and

$$
J_{t}^{H}=\max _{c_{t}, i_{t}} \ln c_{t}+\beta E_{t} J_{t+1}^{H}
$$

$$
\begin{gathered}
c_{t}+i_{t}=w_{t} n_{t}+r_{k, t} k_{t-1}+b u_{t}-\tau_{t}, \\
n_{t+1}=\left(1-\bar{s}\left(1-\chi f_{t+1}\right)\right) n_{t}+f_{t+1} u_{t}, \\
u_{t+1}=\bar{s}\left(1-\chi f_{t+1}\right) n_{t}+\left(1-f_{t+1}\right) u_{t},
\end{gathered}
$$

where $b$ is the flow value of unemployment and $\tau_{t}$ is a lump-sum tax. Optimality implies (5).

Production is the same as it is in the RBC model, except firms must also post vacancies, $v_{t}$, that are subject to a per unit cost, $\kappa$, in order to hire additional workers. The representative firm solves

subject to (6) and

$$
J_{t}^{F}=\max _{k_{t-1}, n_{t}, v_{t}} y_{t}-w_{t} n_{t}-r_{t}^{k} k_{t-1}-\kappa v_{t}+E_{t}\left[x_{t+1} J_{t+1}^{F}\right]
$$

$$
\begin{gathered}
n_{t}=(1-\bar{s}) n_{t-1}+q_{t} v_{t}, \\
v_{t} \geq 0
\end{gathered}
$$

Letting $\lambda_{n, t}$ denote the Lagrange multiplier on the employment law of motion, optimality implies

$$
\begin{gathered}
r_{t}^{k}=\alpha y_{t} / k_{t-1} \\
\lambda_{n, t}=(1-\alpha) y_{t} / n_{t}-w_{t}+(1-\bar{s}) E_{t}\left[x_{t+1} \lambda_{n, t+1}\right] \\
q_{t} \lambda_{n, t}=\kappa-\lambda_{v, t} \\
\lambda_{v, t} v_{t}=0, \quad \lambda_{v, t} \geq 0 .
\end{gathered}
$$

As noted by Hall (2005), there is wage indeterminacy in the absence of additional model structure. We follow the bulk of the literature and assume wages are determined via Nash bargaining between an employed worker and the firm. To operationalize Nash bargaining, define the total sur- 
plus of a new match as $\Lambda_{t}=\lambda_{n, t}+J_{N, t}^{H}-J_{U, t}^{H}$, where $J_{N, t}^{H}$ and $J_{U, t}^{H}$ satisfy the envelope conditions

$$
\begin{gathered}
J_{N, t}^{H}=w_{t}+E_{t}\left[x_{t+1}\left(\left(1-\bar{s}\left(1-\chi f_{t+1}\right)\right) J_{N, t+1}^{H}+\bar{s}\left(1-\chi f_{t+1}\right) J_{U, t+1}^{H}\right)\right], \\
J_{U, t}^{H}=b+E_{t}\left[x_{t+1}\left(f_{t+1} J_{N, t+1}^{H}+\left(1-f_{t+1}\right) J_{U, t+1}^{H}\right)\right] .
\end{gathered}
$$

The equilibrium wage rate maximizes $\left(J_{N, t}^{H}-J_{U, t}^{H}\right)^{\eta} \lambda_{n, t}^{1-\eta}$, where $\eta \in[0,1]$ is the household's bargaining weight. Optimality implies $J_{N, t}^{H}-J_{U, t}^{H}=\eta \Lambda_{t}$ or, equivalently, $\lambda_{n, t}=(1-\eta) \Lambda_{t}$. To derive the equilibrium wage, combine the optimality conditions with $J_{N, t}^{H}, J_{U, t}^{H}$, and (23) to obtain

$$
w_{t}=\eta\left((1-\alpha) y_{t} / n_{t}+\kappa(1-\chi \bar{s}) E_{t}\left[x_{t+1} \theta_{t+1}\right]\right)+(1-\eta) b .
$$

The household's wage rate in period $t$ is a weighted average of the firm's value of a new match and the worker's outside option $b$. The firm's value of a new worker includes the additional output produced plus the discounted expected value of the worker net of separations that occur in period $t+1$.

The aggregate resource constraint is given by

$$
c_{t}+i_{t}+\kappa v_{t}=y_{t}
$$

Equilibrium now consists of sequences of quantities $\left\{y_{t}, k_{t}, c_{t}, n_{t}, i_{t}, u_{t}, u_{t}^{s}, v_{t}, m_{t}, \mathcal{M}_{t}, q_{t}, f_{t}\right\}_{t=0}^{\infty}$, prices $\left\{w_{t}, r_{t}^{k}, \lambda_{n, t}, \lambda_{v, t}\right\}_{t=0}^{\infty}$, and exogenous variables $\left\{a_{t}, \sigma_{a, t}\right\}_{t=0}^{\infty}$ that satisfy (1)-(3), (5)-(6), and (15)-(27), given an expanded initial state $\left\{k_{-1}, n_{-1}, a_{-1}, \sigma_{a,-1}\right\}$ and the same shocks $\left\{\varepsilon_{a, t}, \varepsilon_{\sigma_{a}, t}\right\}_{t=1}^{\infty}$.

3.4 Model BAsed UnCERTAinty We define aggregate uncertainty in each model as the uncertainty surrounding quarterly output growth, and it is standardized to apply the same transformation as the data. As noted in Section 2, our empirical measure of uncertainty captures the common component of uncertainty across many macroeconomic time series. In the models, the uncertainties surrounding all variables are mechanically driven by common exogenous and endogenous components. As a result, they exhibit similar standard deviations and strong positive correlations. Thus, we find it is reasonable to map our empirical uncertainty measure to output growth in our models.

3.5 Solution Method We solve the nonlinear model using the policy function iteration algorithm in Richter et al. (2014), which is based on the theoretical work on monotone operators in Coleman (1991). The algorithm minimizes the Euler equation errors on each node in the state space and computes the maximum change in the policy functions. It then replaces the initial guess with the updated policy functions and iterates until the maximum change is below the tolerance level.

We discretize the endogenous state variables and TFP, and approximate the exogenous volatility process and future level shock using the $N$-state Markov chain in Rouwenhorst (1995). The Rouwenhorst method is useful because it does not require us to interpolate along the volatility state, making the solution more accurate and faster than quadrature methods. To obtain initial con- 
jectures for the nonlinear policy functions, we solve the linear analogue of our nonlinear model with Sims's (2002) gensys algorithm. Appendix B describes the solution algorithm in more detail.

3.6 Total Variance Decompositions To decompose the variance of a model outcome into its structural components, we cannot use standard methods such as linear forecast error variance decompositions (FEVDs). Instead, we follow Isakin and Ngo (2020) and use a Total Variance Decomposition (TVD). Based on the law of total variance, the TVD takes into account both nonlinearities in the model and multiplicative interaction effects that occur between level and volatility shocks. Linear FEVDs miss both of those effects, while generalized FEVDs based on generalized impulse response functions (Lanne and Nyberg, 2016) miss the multiplicative interaction effects.

Formally, let $\varepsilon_{t}=\left[\varepsilon_{1, t}, \ldots, \varepsilon_{n, t}\right]^{\prime}$ denote a vector of shocks and $y_{t}=f\left(\varepsilon_{t}\right)$ denote an outcome determined by some possibly nonlinear function $f$. We would like to decompose the variance of the $h$-step ahead forecast error in period $t, V_{t}\left[y_{t+h}-E_{t} y_{t+h}\right]=V_{t}\left[y_{t+h}\right]$, into components attributable to each shock and their nonlinear interactions. To achieve this, we consider two TVDs. First, let $\left\{\varepsilon_{-j}\right\}_{t+1}^{t+h}$ denote a realization of all shocks except $j$ in periods $t+1$ to $t+h$. Using this set of shocks as a conditioning random variable and applying the law of total variance to $V_{t}\left[y_{t+h}\right]$ yields

$$
V_{t}\left[y_{t+h}\right]=\underbrace{E_{t}\left[V_{t}\left[y_{t+h} \mid\left\{\varepsilon_{-j}\right\}_{t+1}^{t+h}\right]\right]}_{\text {Total Effect of shock } j}+V_{t}\left[E_{t}\left[y_{t+h} \mid\left\{\varepsilon_{-j}\right\}_{t+1}^{t+h}\right]\right] .
$$

The first term computes the variance of $y_{t+h}$ driven by randomness in the path of the $j$ th shock $\left\{\varepsilon_{j}\right\}_{t+1}^{t+h}$, and then averages over all possible paths of the other shocks $\left\{\varepsilon_{-j}\right\}_{t+1}^{t+h}$. Therefore, this term captures the contribution of shock $j$ to the total variance. Importantly, this contribution contains both its direct and interaction effects. The second term captures the residual variance due to the other shocks, which includes their direct effects and interactions excluding those with shock $j$.

The second TVD conditions on the $j$ th shock, $\left\{\varepsilon_{j}\right\}_{t+1}^{t+h}$, so the law of total variance implies

$$
V_{t}\left[y_{t+h}\right]=E_{t}\left[V_{t}\left[y_{t+h} \mid\left\{\varepsilon_{j}\right\}_{t+1}^{t+h}\right]\right]+\underbrace{V_{t}\left[E_{t}\left[y_{t+h} \mid\left\{\varepsilon_{j}\right\}_{t+1}^{t+h}\right]\right]}_{\text {Direct Effect of shock } j} .
$$

In this case, the first term captures the variance contribution of all shocks except $j$, including both their direct and interaction effects. More importantly, the second term captures the residual variance driven by only the direct effect of the $j$ th shock. Computing the decompositions in (28) and (29) for each shock $j=1, \ldots, n$ allows us to parse out the direct and interaction effects of shock $j$.

Examples We apply the TVD method to two simple models of an outcome $y_{t}=f\left(\varepsilon_{1, t}, \varepsilon_{2, t}\right)$ driven by two independent standard normal shocks $\varepsilon_{1, t}, \varepsilon_{2, t} \sim N(0,1)$. First suppose $f$ is linear so

$$
y_{t}=\sigma_{1} \varepsilon_{1, t}+\sigma_{2} \varepsilon_{2, t}, \quad \sigma_{1}, \sigma_{2}>0
$$


Conditioning on shock 1 yields

$$
V_{t}\left[y_{t+h}\right]=E_{t}\left[V_{t}\left[\sigma_{1} \varepsilon_{1, t+h}+\sigma_{2} \varepsilon_{2, t+h} \mid\left\{\varepsilon_{1}\right\}_{t+1}^{t+h}\right]\right]+V_{t}\left[E_{t}\left[\sigma_{1} \varepsilon_{1, t+h}+\sigma_{2} \varepsilon_{2, t+h} \mid\left\{\varepsilon_{1}\right\}_{t+1}^{t+h}\right]\right]
$$

which simplifies to $V_{t}\left[y_{t+h}\right]=\sigma_{2}^{2}+\sigma_{1}^{2}$. Hence, the total contribution of shock 2 is $\sigma_{2}^{2}$, while the direct effect of shock 1 is $\sigma_{1}^{2}$. Conditioning on shock 2 yields $V_{t}\left[y_{t+h}\right]=\sigma_{1}^{2}+\sigma_{2}^{2}$. Therefore, the total contribution of shock $j \in\{1,2\}, \sigma_{j}^{2}$, is entirely due to direct effects. Under a linear specification, there are no interaction effects and the sum of the total contributions is equal to the total variance.

Second, consider a simple model of stochastic volatility,

$$
\begin{gathered}
y_{t}=\sigma_{t} \varepsilon_{1, t}, \\
\sigma_{t}=\bar{\sigma}+\sigma_{s v} \varepsilon_{2, t} .
\end{gathered}
$$

In this setting, shock 1 directly impacts the level of $y_{t}$, while shock 2 only affects $y_{t}$ through its impact on the volatility of the level shock. ${ }^{7}$ Conditioning on shock 1 and applying the TVD yields

$$
V_{t}\left[y_{t+h}\right]=E_{t}\left[V_{t}\left[\left(\bar{\sigma}+\sigma_{s v} \varepsilon_{2, t+h}\right) \varepsilon_{1, t+h} \mid\left\{\varepsilon_{1}\right\}_{t+1}^{t+h}\right]\right]+V_{t}\left[E_{t}\left[\left(\bar{\sigma}+\sigma_{s v} \varepsilon_{2, t+h}\right) \varepsilon_{1, t+h} \mid\left\{\varepsilon_{1}\right\}_{t+1}^{t+h}\right]\right],
$$

which simplifies to $V_{t}\left[y_{t+h}\right]=\sigma_{s v}^{2}+\bar{\sigma}^{2}$. Hence, the total contribution of shock 2 is $\sigma_{s v}^{2}$, while the direct effect of shock 1 is $\bar{\sigma}^{2}$. Conditioning on shock 2 yields $V_{t}\left[y_{t+h}\right]=\left(\bar{\sigma}^{2}+\sigma_{s v}^{2}\right)+0$, so the total contribution of shock 1 is $\bar{\sigma}^{2}+\sigma_{s v}^{2}$, while the direct effect of shock 2 is zero. The share of shock 1 's total variance contribution due to direct effects is $\bar{\sigma}^{2} /\left(\sigma_{s v}^{2}+\bar{\sigma}^{2}\right)$, while shock 2's contribution is entirely driven by interaction effects with shock 1 . Note that in this nonlinear setting, the total contributions no longer sum to the total variance due to double counting of the interaction effects.

\section{CALIBRATION EXERCISE}

This section calibrates our models as a first pass at examining the relationship between output and aggregate uncertainty. The first calibration, labeled "Data", sets $\sigma_{s v}$ and $\bar{\sigma}_{a}$ to target the standard deviations of aggregate uncertainty and detrended output as reported in Figure 1. The second calibration, labeled "Large", sets $\sigma_{s v}$ to a much larger value to highlight the effects of targeting aggregate uncertainty and place a plausible upper bound on the importance of uncertainty shocks. Specifically, $\sigma_{s v}$ is set so that a one standard deviation increase in $\sigma_{a, t}$ doubles its mean value. This leads to a value of $\sigma_{s v}$ that is close to the values in Fernández-Villaverde and Guerrón-Quintana (2020) and Leduc and Liu (2016). Given $\sigma_{s v}$, we again set $\bar{\sigma}_{a}$ to target the standard deviation of detrended output. All other parameter values are set to conventional values reported in Appendix D.

Table 2 reports the calibrated values of $\bar{\sigma}_{a}$ and $\sigma_{s v}$ for each model under the Data and Large

\footnotetext{
${ }^{7} \mathrm{We}$ abstract from requiring $\sigma_{t}>0$ for simplicity. The volatility process is in logs when we estimate our model.
} 


\begin{tabular}{lccccccc}
\hline & \multicolumn{3}{c}{ Data Calibration } & & \multicolumn{3}{c}{ Large Calibration } \\
\cline { 2 - 3 } & RBC & NK & DMP & & RBC & NK & DMP \\
\hline Level Shock $\left(\bar{\sigma}_{a}\right)$ & 0.0127 & 0.0123 & 0.0061 & & 0.0082 & 0.0080 & 0.0037 \\
Volatility Shock $\left(\sigma_{s v}\right)$ & 0.0548 & 0.0548 & 0.0193 & & 0.4500 & 0.4500 & 0.3543 \\
\hline
\end{tabular}

Table 2: Standard deviations. The RBC and NK models are quarterly and the DMP model is monthly.

calibrations. A volatility shock under the Data calibration increases average volatility in the model between $2 \%$ and $5 \% .{ }^{8}$ When we mechanically increase $\sigma_{s v}$ in the Large calibration, the value of $\bar{\sigma}_{a}$ decreases by $35 \%$ to $40 \%$ in order to achieve the same standard deviation of output. This means the fluctuations in TFP volatility increase under this calibration, but average TFP volatility decreases.

4.1 Simulation Results Table 3 reports key moments from simulations of each model under the Data and Large calibrations. First consider the RBC model under the Data calibration. The model matches the standard deviations of aggregate uncertainty and output, but uncertainty is acyclical, in contrast to the strong negative correlation between uncertainty and output in the data.

There are two possible explanations for the weak correlation. Output and uncertainty are entirely driven by orthogonal shocks or there are offsetting causal mechanisms (e.g., first moment shocks induce a positive correlation, while volatility shocks induce a negative correlation). The variance decompositions show the former explanation is correct. Focusing on output, level shocks explain $100 \%$ of the variance, while volatility shocks account for $0.68 \%$. Recall the decomposition is not additive due to double counting of interaction effects. Using the method in Section 3.6, we find the direct effects account for over $99 \%$ of the level shock variance contribution and only $0.27 \%$ of the volatility shock contribution. Hence, output variance is almost entirely driven by the direct effect of level shocks, with very little role for volatility shocks or their interaction with level shocks.

In contrast, the decomposition of aggregate uncertainty emphasizes the importance of volatility shocks, which explain $100 \%$ of the variance of uncertainty. There is no role for level shocks. Since these shares are almost entirely due to direct effects, changes in aggregate uncertainty are exogenous and unrelated to changes in output. This explains the negligible correlation in the RBC model.

We obtain similar results in the NK model. This finding echoes Born and Pfeifer (2014), who find small effects of aggregate uncertainty shocks in a medium-scale NK model with multiple sources of exogenous volatility. In line with their reasoning, volatility shocks are too small and have too weak of a transmission to play a meaningful role in business cycle fluctuations. This result does not contradict papers that show uncertainty shocks may worsen recessionary episodes (Cacciatore and Ravenna, 2021; Fernández-Villaverde et al., 2015). Our point is simply that these ef-

\footnotetext{
${ }^{8}$ Following Born and Pfeifer (2021), we could estimate a TFP process outside the model. Using Hamilton filtered TFP data, a volatility shock would increase average volatility by $10 \%$, close to our estimates under the data calibration.
} 


\begin{tabular}{|c|c|c|c|c|c|c|}
\hline & \multicolumn{3}{|c|}{ Data Calibration } & \multicolumn{3}{|c|}{ Large Calibration } \\
\hline & $\mathrm{RBC}$ & NK & DMP & $\mathrm{RBC}$ & NK & DMP \\
\hline \multicolumn{7}{|l|}{ Uncertainty } \\
\hline$S D(\mathcal{U})$ & 5.93 & 5.93 & 5.93 & 45.26 & 45.29 & 56.09 \\
\hline$S D(\tilde{y})$ & 3.15 & 3.15 & 3.15 & 3.15 & 3.15 & 3.15 \\
\hline $\operatorname{Corr}(\mathcal{U}, \tilde{y})$ & -0.01 & 0.01 & -0.82 & 0.00 & 0.00 & -0.09 \\
\hline \multicolumn{7}{|c|}{ Output Decomposition } \\
\hline Level Total & 100.00 & 100.00 & 100.00 & 99.87 & 99.87 & 99.75 \\
\hline Volatility Total & 0.68 & 0.68 & 0.19 & 36.14 & 36.15 & 43.27 \\
\hline Level Direct & 99.32 & 99.32 & 99.81 & 63.94 & 63.93 & 56.90 \\
\hline Volatility Direct & 0.27 & 0.27 & 0.29 & 0.37 & 0.37 & 0.58 \\
\hline \multicolumn{7}{|c|}{ Uncertainty Decomposition } \\
\hline Level Total & 0.00 & 0.04 & 73.50 & 0.00 & 0.00 & 2.00 \\
\hline Volatility Total & 100.00 & 99.96 & 26.79 & 100.00 & 100.00 & 99.46 \\
\hline Level Direct & 98.30 & 98.54 & 99.60 & 25.38 & 52.02 & 27.12 \\
\hline Volatility Direct & 100.00 & 100.00 & 98.89 & 100.00 & 100.00 & 98.75 \\
\hline
\end{tabular}

Table 3: Simulated moments and variance decomposition. The standard deviations are percents and $\tilde{y}$ is detrended output. "Direct" refers to the share of "Total" attributable to direct effects based on (28) and (29).

fects are not widespread enough to play a major role in explaining business cycles. Thus, they cannot generate a strong negative correlation between aggregate uncertainty and output in the model.

Now turn to the DMP model under the Data calibration. In sharp contrast to the RBC and NK models, it features a strong negative correlation between output and uncertainty $(-0.82)$ that exceeds the data. Furthermore, the variance decompositions show that level shocks are the common driver of output and uncertainty. Their direct effects explain almost $100 \%$ of output variance and $74 \%$ of uncertainty variance. This shows the negative correlation is driven by first moment shocks causing fluctuations in uncertainty, rather than volatility shocks generating fluctuations in output.

Endogenous Uncertainty in the DMP Model The law of motion for unemployment provides a powerful propagation mechanism from level shocks to uncertainty (Bernstein et al., 2021). Consider the simplest version of this equation obtained by combining (18), (20), and (21) with $\chi=0$,

$$
u_{t+1}=u_{t}+\bar{s}\left(1-u_{t}\right)-f_{t+1} u_{t}
$$

Computing the period- $t$ conditional variance of 1 -period ahead unemployment yields

$$
V_{t}\left[u_{t+1}\right]=u_{t}^{2} V_{t}\left[f_{t+1}\right]
$$

which shows that the variance of future unemployment is increasing in current unemployment. Intuitively, for a given job finding rate variance, a larger mass of unemployed workers will generate more variability in the future total outflow $f_{t+1} u_{t}$, and hence more variance in future unemploy- 
ment. Since unemployment uncertainty directly affects output uncertainty through the production function, the DMP model features endogenous fluctuations in uncertainty driven by level shocks. ${ }^{9}$

Large Uncertainty Shocks Now consider the Large calibration. We focus on the DMP model, given its relative success under the Data calibration, though the results are similar across all three models. In this case, the standard deviation of uncertainty (56\%) is over nine times larger than the data, while its correlation with output $(-0.09)$ is close to zero. Therefore, when uncertainty in the model is excessively volatile, its co-movement with real activity is very weak relative to the data.

The negligible correlation is due to the different transmission mechanisms of volatility shocks to output and uncertainty and is visible in the variance decompositions. Focusing on output, level shocks account for almost $100 \%$ of the variance, while volatility shocks account for $43 \%$. The direct effects account for $57 \%$ of the level shock variance contribution but only $0.58 \%$ of the volatility shock contribution. Thus, the transmission of volatility shocks to output is almost entirely due to their multiplicative interaction with level shocks. Volatility shocks matter only because they exogenously and stochastically vary the transmission strength of first moment shocks. The direct effects of volatility shocks that operate through changes in risk have very little impact on output dynamics.

In contrast, volatility shocks transmit to uncertainty entirely through direct effects. The direct effects of volatility account for almost $99 \%$ of the volatility shock variance contribution, which itself explains $99 \%$ of the variance of uncertainty. Therefore, fluctuations in uncertainty are an exogenous phenomenon, which implies they are unrelated to level shocks and fluctuations in output. This difference in transmission results in a negligible correlation between output and uncertainty.

4.2 Generalized Impulse Responses The results of our Large calibration are not driven by implausible responses to uncertainty shocks. To see this, Figure 2 plots generalized impulse responses of output and unemployment to a 2 standard deviation uncertainty shock in the DMP model. ${ }^{10}$ These responses are informative about the direct contribution of the uncertainty shock. Under the Large calibration, the shock causes a $60 \%$ increase in level shock volatility, a peak decline in output of about $0.035 \%$, and a peak increase in the unemployment rate of about $1.25 \%$, which translates into only a 0.07 percentage point change in the unemployment rate. Although the real effects are small in an absolute sense, they are similar to the responses in the literature on which the Large calibration is based. For example, the response of the unemployment rate in Leduc and Liu (2016) to a similar uncertainty shock peaks at $1.8 \%$. We conclude that such responses are vastly inconsistent with the standard deviation of aggregate uncertainty and its correlation with output.

\footnotetext{
${ }^{9}$ Unlike the DMP model, neither the RBC nor the NK model contain a strong mechanism for generating endogenous fluctuations in aggregate uncertainty. As discussed in Atkinson et al. (2021), these models fail to generate endogenous movements in uncertainty because endogenous outcomes are essentially log-linear in first moment TFP shocks.

${ }^{10}$ Following Koop et al. (1996), the response of $x_{t+h}$ over horizon $h$ is given by $\mathcal{G}_{t}\left(x_{t+h} \mid \varepsilon_{s v, t+1}=2, \mathbf{z}_{t}\right)=$ $100 \times\left(E_{t}\left[x_{t+h} \mid \varepsilon_{s v, t+1}=2, \mathbf{z}_{t}\right] / E_{t}\left[x_{t+h} \mid \mathbf{z}_{t}\right]-1\right)$, where $\mathbf{z}_{t}$ is the state vector and 2 is the shock size in period $t+1$.
} 


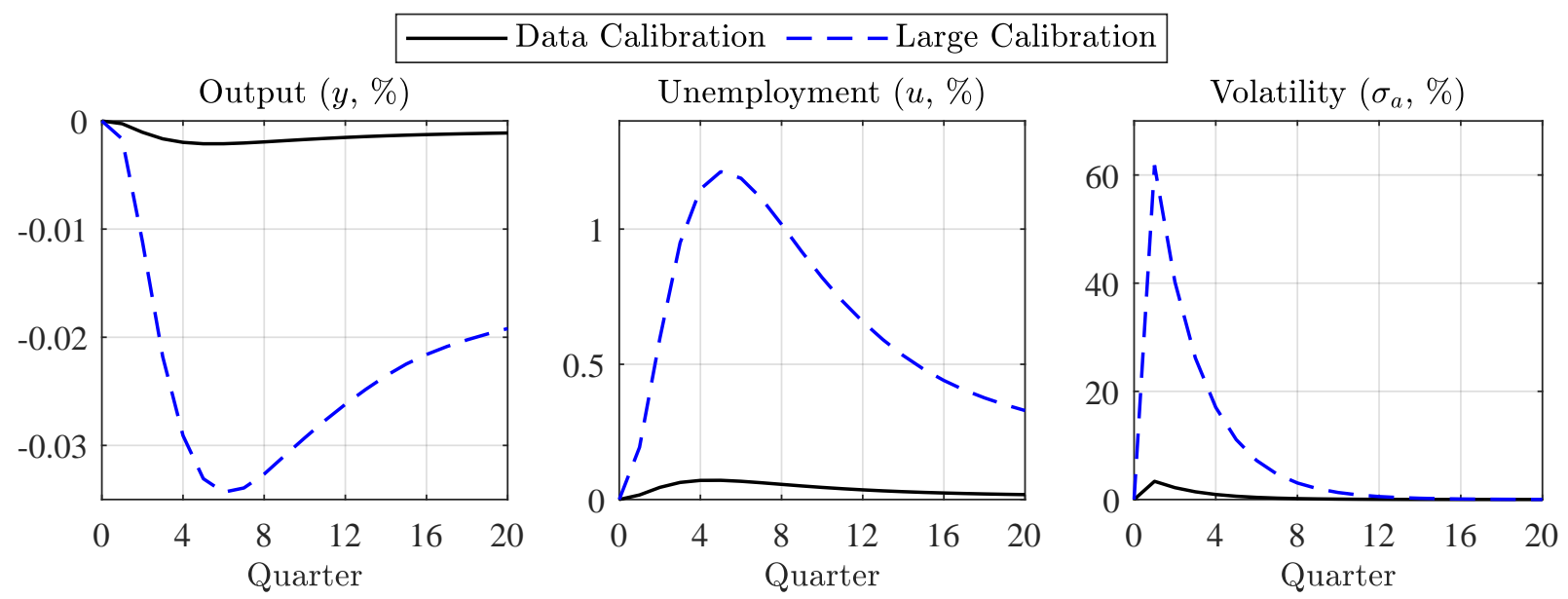

Figure 2: Generalized impulse responses to a 2 standard deviation positive volatility shock.

Under the Data calibration, which targets the standard deviation of uncertainty, the responses change dramatically. Due to the smaller $\sigma_{s v}$, the responses are substantially dampened so that uncertainty shocks have a negligible effect on real activity, in line with the variance decompositions.

\section{Estimated Model of UnCERTAinty}

Among the set of textbook models, only the search and matching model generates the negative correlation between output and uncertainty in the data. This section estimates a version of this model and finds that it can jointly explain variation in macroeconomic aggregates and uncertainty.

To credibly match both the dynamics of consumption and investment, we introduce investment adjustment costs. Following Jermann (1998), the law of motion for capital, (3), is replaced by

$$
k_{t}=(1-\delta) k_{t-1}+\left(a_{1}+\frac{a_{2}}{1-1 / \nu}\left(\frac{i_{t}}{k_{t-1}}\right)^{1-1 / \nu}\right) k_{t-1},
$$

where $\nu>0$ determines the adjustment cost and $a_{1}=\delta /(1-\nu)$ and $a_{2}=\delta^{1 / \nu}$ are chosen so there are no adjustment costs in steady state. The optimality condition for investment (5) is replaced by

$$
\frac{1}{a_{2}}\left(\frac{i_{t}}{k_{t-1}}\right)^{1 / \nu}=E_{t}\left[x_{t+1}\left(r_{t+1}^{k}+\frac{1}{a_{2}}\left(\frac{i_{t+1}}{k_{t}}\right)^{1 / \nu}\left(1-\delta+a_{1}\right)+\frac{1}{\nu-1} \frac{i_{t+1}}{k_{t}}\right)\right] .
$$

5.1 Estimation Method The model is estimated using quarterly data from 1963 to 2019. Appendix A provides detailed descriptions of our data sources and how the data was transformed.

Parameter Identification We estimate 10 parameters: $b, \phi, \eta, \kappa, \chi, \nu, \rho_{a}, \bar{\sigma}_{a}, \rho_{s v}, \sigma_{s v}$. While they are jointly estimated, we can heuristically describe how each parameter is identified based on specific moments in the data. Table 4 summarizes the identification scheme. The outside option $b$ 
governs the economy's “fundamental surplus fraction" (Ljungqvist and Sargent, 2017), defined as the upper bound on the fraction of a worker's output that is allocated to vacancy creation. It is well understood that a small fundamental surplus fraction driven by a large $b$ is crucial to deliver realistic volatilities of unemployment and vacancies (Hagedorn and Manovskii, 2008; Ljungqvist and Sargent, 2017). While $b$ affects overall labor market volatility, the matching elasticity, $\phi$, affects the relative volatilities of vacancies and unemployment. When the elasticity is higher, an increase in matches requires a smaller increase in unemployed searching and hence unemployment. Therefore, when matches fluctuate, unemployment fluctuates less relative to vacancies. Hence, we estimate $b$ and $\phi$ by targeting the standard deviations of detrended unemployment and vacancies in the data.

\begin{tabular}{lc}
\hline Parameters & Identifying Moments \\
\hline$b, \phi$ & $S D(\tilde{u}), S D(\tilde{v})$ \\
$\eta$ & $\operatorname{Cov}(\tilde{w}, \tilde{\ell}) / \operatorname{Var}(\tilde{\ell})$ \\
$\kappa, \chi$ & $E(u), E(f)$ \\
$\nu$ & $S D(\tilde{c}), S D(\tilde{\imath}), A C(\tilde{c}), A C(\tilde{\imath})$ \\
$\rho_{a}, \bar{\sigma}_{a}$ & $A C(\tilde{y}), S D(\tilde{y})$ \\
$\rho_{s v}, \sigma_{s v}$ & $A C(\mathcal{U}), S D(\mathcal{U}), \operatorname{Corr}(\mathcal{U}, \tilde{y})$ \\
\hline
\end{tabular}

Table 4: Identification heuristic. E, SD, $\operatorname{Var}, A C, C o r r$, and $C o v$ denote the mean, standard deviation, variance, autocorrelation, correlation, and covariance in our sample. A tilde denotes a detrended variable.

The Nash bargaining parameter, $\eta$, governs the responsiveness of wages to changes in the marginal product of labor, which is driven by labor productivity, $\ell \equiv y / n$. Hence, we follow Hagedorn and Manovskii (2008) and estimate $\eta$ by targeting the empirical elasticity of detrended wages with respect to detrended labor productivity. The last two labor market parameters, $\kappa$ and $\chi$, are estimated by targeting the average unemployment and job finding rates. We pin down the parameters of the TFP process, $\rho_{a}$ and $\bar{\sigma}_{a}$, by targeting the standard deviation and autocorrelation of detrended output. The investment adjustment cost parameter, $\nu$, is then identified by targeting the standard deviations and autocorrelations of detrended consumption and investment. Finally, the parameters of the volatility process are pinned down by targeting the standard deviation, autocorrelation, and cyclicality of the real uncertainty series constructed by Ludvigson et al. (2021). ${ }^{11}$

The moments are estimated with a Generalized Method of Moments (GMM) and stored in $\hat{\Psi}_{T}^{D}$.

Estimation Procedure Five parameters are set externally. The time discount factor, $\beta$, is set to 0.9983, which implies an annual real interest rate of $2 \%$. The capital depreciation rate, $\delta=0.0079$, matches the annual average rate on private fixed assets and consumer durable goods converted to a monthly rate. The income share of capital, $\alpha=0.3888$, equals the complement of the quarterly

\footnotetext{
${ }^{11}$ In the absence of exogenous volatility shocks, all uncertainty fluctuations would be endogenous and its correlation with output would be close to -1 . Since output barely responds to exogenous volatility shocks, increasing the exogenous component of uncertainty fluctuations by increasing $\sigma_{s v}$ and $\rho_{s v}$ also lowers the correlation with output.
} 
labor share in the non-farm business sector. The steady-state job separation rate, $\bar{s}$, is set to 0.0328 to match its sample mean. Finally, the steady state job filling rate is set to 0.3306 . This corresponds to a quarterly filling rate of 0.7, which matches Den Haan et al. (2000) and Leduc and Liu (2016).

Conditional on the GMM estimates of the target moments, the remaining parameters are estimated by applying a Simulated Method of Moments (SMM) to our nonlinear search and matching model. For parameterization $\theta$ and shocks $\mathcal{E}$, we solve the model and simulate it $R=1,000$ times for $T$ periods. The analogues of the targets are the mean moments across the $R$ simulations, $\bar{\Psi}_{R, T}^{M}(\theta, \mathcal{E})$. The parameter estimates, $\hat{\theta}$, are obtained by minimizing the following loss function:

$$
J(\theta, \mathcal{E})=\left[\hat{\Psi}_{T}^{D}-\bar{\Psi}_{R, T}^{M}(\theta, \mathcal{E})\right]^{\prime}\left[\hat{\Sigma}_{T}^{D}(1+1 / R)\right]^{-1}\left[\hat{\Psi}_{T}^{D}-\bar{\Psi}_{R, T}^{M}(\theta, \mathcal{E})\right]
$$

where $\hat{\Sigma}_{T}^{D}$ is the diagonal of the GMM estimate of the variance-covariance matrix. A Monte Carlo procedure is used to calculate the standard errors on the parameters. ${ }^{12}$ We run our SMM algorithm $N_{s}=200$ times, each time conditional on a particular sequence of shocks $\mathcal{E}^{s}$ but holding fixed the empirical targets, $\hat{\Psi}_{T}^{D}$, and weighting matrix, $\hat{\Sigma}_{T}^{D}$, used in the loss function. Given the set of parameter estimates $\left\{\hat{\theta}^{s}\right\}_{s=1}^{N_{s}}$, we report the mean, $\bar{\theta}=\sum_{s=1}^{N_{s}} \hat{\theta}^{s} / N_{s}$, and standard errors. ${ }^{13}$ While this method is numerically intensive, it has two major benefits. First, it provides more reliable estimates of the standard errors than using the asymptotic variance of the estimator, which is more common. Second, it is an effective way to determine whether the parameters are identified and check for multiple modes. Appendix C provides a step-by-step outline of our estimation procedure.

The targets are based on quarterly data in percent deviations from a Hamilton (2018) filtered trend. ${ }^{14}$ Each period in the model is 1 month, so we aggregate the simulated data to a quarterly frequency. We then detrend the simulated data by computing percent deviations from the time average, so the units of the moments are comparable to their counterpart in the data. We compute uncertainty over a 3-month horizon $(h=3)$ in order to match the horizon of the real uncertainty series.

5.2 Estimation Results Table 5a reports the estimated parameters and their standard errors. All parameters are precisely estimated, with mean estimates that are well within conventional ranges. For example, the matching elasticity, $\phi$, is within the range of elasticities estimated in the data (Mortensen and Nagypal, 2007; Petrongolo and Pissarides, 2001). The outside option, $b$, is just below the value in Hagedorn and Manovskii (2008), and the search duration, $\chi$, is close the value in Shimer (2005). The small standard errors on the parameter estimates indicate that our identification scheme is strong. In particular, the data is pinning down the parameters governing the volatility

\footnotetext{
${ }^{12}$ Ruge-Murcia (2012) applies SMM to several nonlinear business cycle models and finds that asymptotic standard errors tend to overstate the variability of the estimates. This underscores the importance of using Monte Carlo methods.

${ }^{13}$ The practice of re-estimating with different sequences of shocks follows the recommendation of Fabio Canova (see http: / / apps.eui.eu/Personal/Canova/Teachingmaterial/Smm_eui2014.pdf, slide 16).

${ }^{14}$ Specifically, we regress each time series on its most recent 4 lags following an 8 quarter window. Hodrick (2020) shows this approach is more accurate than an HP filter when time series, such as ours, are first-difference stationary.
} 


\begin{tabular}{lcclcc}
\hline Parameter & Mean & SE & Parameter & Mean & SE \\
\hline Search Duration $(\chi)$ & 0.5463 & 0.0011 & Investment Adjustment Cost $(\nu)$ & 5.4153 & 0.0214 \\
Vacancy Posting Cost $(\kappa)$ & 1.1922 & 0.0090 & Level Shock Persistence $\left(\rho_{a}\right)$ & 0.9239 & 0.0006 \\
Outside Option $(b)$ & 0.9380 & 0.0003 & Level Shock SD $\left(\bar{\sigma}_{a}\right)$ & 0.0105 & 0.0000 \\
Matching Elasticity $(\phi)$ & 0.4940 & 0.0004 & Volatility Shock Persistence $\left(\rho_{s v}\right)$ & 0.9438 & 0.0008 \\
Bargaining Weight $(\eta)$ & 0.1465 & 0.0007 & Volatility Shock SD $\left(\sigma_{s v}\right)$ & 0.0157 & 0.0001 \\
\hline
\end{tabular}

(a) Parameter estimates and standard errors.

\begin{tabular}{lccclccc}
\hline Target & Data & SE & Model & Target & Data & SE & Model \\
\hline$E(u)$ & 5.97 & 0.25 & 5.93 & $S D(\mathcal{U})$ & 5.93 & 0.62 & 6.08 \\
$E(f)$ & 41.88 & 1.26 & 41.90 & $A C(\mathcal{U})$ & 0.89 & 0.04 & 0.89 \\
$S D(\tilde{y})$ & 3.15 & 0.31 & 3.66 & $\operatorname{Corr}(\mathcal{U}, \tilde{y})$ & -0.60 & 0.08 & -0.62 \\
$S D(\tilde{c})$ & 2.06 & 0.17 & 2.02 & $A C(\tilde{y})$ & 0.90 & 0.03 & 0.88 \\
$S D(\tilde{\imath})$ & 8.68 & 0.82 & 7.31 & $A C(\tilde{c})$ & 0.88 & 0.03 & 0.92 \\
$S D(\tilde{u})$ & 21.36 & 1.98 & 21.17 & $A C(\tilde{\imath})$ & 0.89 & 0.04 & 0.86 \\
$S D(\tilde{v})$ & 21.64 & 2.08 & 21.72 & $\operatorname{Slope}(\tilde{w}, \tilde{\ell})$ & 0.63 & 0.09 & 0.63 \\
\hline
\end{tabular}

(b) Data and simulated moments. The overall fit is $J=8.8$ with p-value 0.067 .

Table 5: Estimation results.

process, which is crucial for decomposing the exogenous and endogenous sources of uncertainty.

The success of our estimation is also clear from the simulated moments. Table $5 \mathrm{~b}$ reports the mean and standard errors of the target moments as well as the simulated moments based on the estimated mean parameterization. Importantly, the model matches the standard deviation and autocorrelation uncertainty as well as its correlation with output. In addition, the model closely matches all of the real activity and labor moments. The fit is sufficiently strong that the model passes an overidentifying restrictions test at the $5 \%$ confidence level. These results provide confidence that the DMP model provides a credible description of real activity and uncertainty over the business cycle.

\begin{tabular}{lcc}
\hline & Output Decomposition & Uncertainty Decomposition \\
\hline Level Total & 100.00 & 43.16 \\
Volatility Total & 0.23 & 57.41 \\
Level Direct & 99.77 & 98.67 \\
Volatility Direct & 0.21 & 99.00 \\
\hline
\end{tabular}

Table 6: Variance decompositions in the estimated DMP model.

Variance Decompositions The qualitative results from our calibration exercise carry through to our estimated model. Following the same methods, Table 6 reports the variance decompositions of output and uncertainty in the estimated model. Similar to the calibration exercise, there is almost no role for volatility shocks in explaining output variance, while the direct effect of level shocks explains $43 \%$ of the variance in uncertainty. In the calibration exercise it was $74 \%$, but the DMP 
model overshot the correlation between uncertainty and output. The lower but still significant fraction of endogenous uncertainty reflects that the estimated model matches the negative correlation.
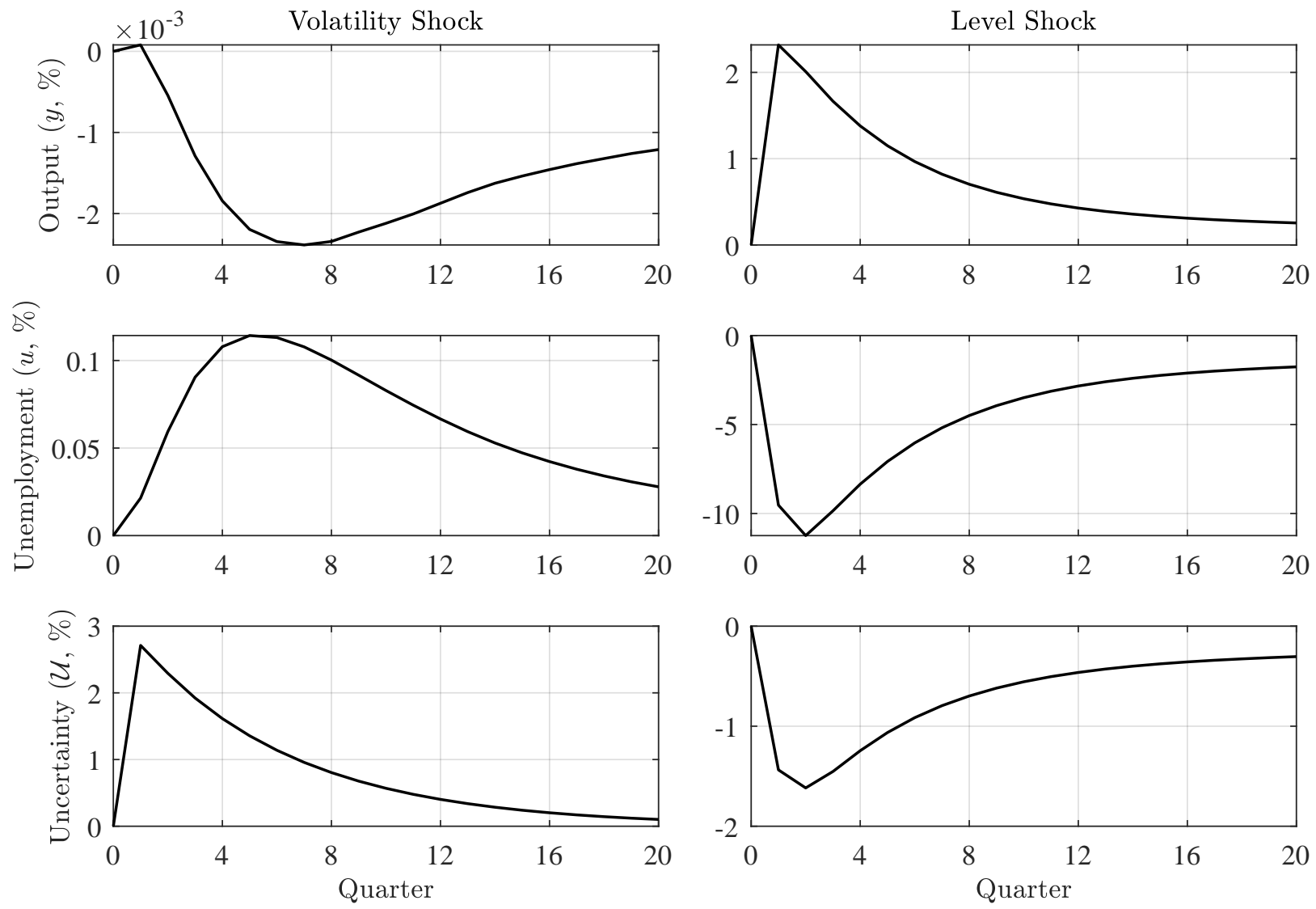

Figure 3: Generalized impulse responses to 2 standard deviation positive level and volatility shocks.

Generalized Impulse Responses To further dissect the model's dynamics, Figure 3 plots generalized impulse responses of output, unemployment, and uncertainty to 2 standard deviation level and volatility shocks. In line with the variance decompositions, all outcomes respond strongly to the level shock, while only uncertainty significantly responds to the volatility shock. Once again, these results show that a significant fraction of uncertainty fluctuations are endogenous and volatility shocks have small real effects when the model matches uncertainty and output dynamics in the data.

5.3 IMPLICATIONS FOR VAR MODELS While generalized impulse responses are useful for understanding the propagation of structural shocks, they are difficult to directly compare to the data. Empirically, applying identification restrictions to estimated vector autoregressions (VARs) is required to tease out the causal links between uncertainty and output. Consider a bivariate VAR,

$$
Y_{t}=\sum_{l=1}^{L} A_{l} Y_{t-l}+v_{t}
$$


where $Y_{t}$ is a vector containing output and uncertainty, $v_{t}$ is a vector of reduced-form shocks, and $A_{l}$ is a matrix of parameters. The number of lags $L=3$ is based on the Akaike Information Criterion.

A common way to estimate the response of output to uncertainty shocks is by ordering uncertainty first in $Y_{t}$ and using a Cholesky decomposition to obtain the identified structural shocks (Basu and Bundick, 2017; Leduc and Liu, 2016; Oh, 2020). In this setting, uncertainty shocks can affect uncertainty and output on impact, while output shocks can only affect output contemporaneously. Importantly, this assumption is violated in our estimated model, since the true structural uncertainty shocks have a negligible effect on output, while output (level) shocks do affect uncertainty. To test whether the recursive identification scheme can identify the true structural output responses, we estimate the VAR model on actual and simulated data and compare the identified responses. We simulate the monthly DMP model 1,000 times to produce artificial data series with 684 monthly observations. This provides 228 quarterly observations - the same as in our structural estimation.

Figure 4 reports the impulse responses of output and uncertainty to uncertainty shocks using actual and simulated data under the recursive identification scheme. The responses based on actual data are similar to those in the literature: a positive uncertainty shock raises uncertainty and lowers output on impact. Importantly, we obtain similar responses using our simulated data, so the VAR produces similar responses of output to an identified uncertainty shock even though it violates the empirical identification assumption. This means the recursive identification scheme with uncertainty ordered first does not necessarily identify the true structural uncertainty shocks. Appendix E shows our VAR results are robust to also including consumption, investment, and unemployment.

Only the level shock affects uncertainty and output on impact in the simulated data. This means the identified "structural" shock must be correlated with the level shock from the DMP model. We confirm this intuition by estimating the VAR model on simulated monthly data (i.e., the frequency of the model) and correlating the identified structural shocks with the true structural shocks. While the identified uncertainty shock has a correlation of 0.84 with the true structural uncertainty shock, it also has a correlation of -0.46 with the true structural level shock, confirming it is contaminated.

To confirm our results are not driven by spurious correlations, we check whether the VAR can identify the true structural shocks under the recursive ordering implied by our model. When we repeat the simulation exercise with output ordered first, the identified output shock has a correlation of 0.99 with the true level shock and 0 with the true uncertainty shock. The identified uncertainty shock has a correlation of 0.96 with the true uncertainty shock and 0 with the level shock. This shows the VAR is able to identify the true structural shocks under the correct ordering assumptions.

In reality, the empirical relationships in the data are more complicated than our simple model is able to capture. In recent work, Ludvigson et al. (2021) exploit these complexities to develop a set and narrative based identification approach that plausibly uncovers the causal relationships between real uncertainty and output without relying on recursive identification methods that they find 

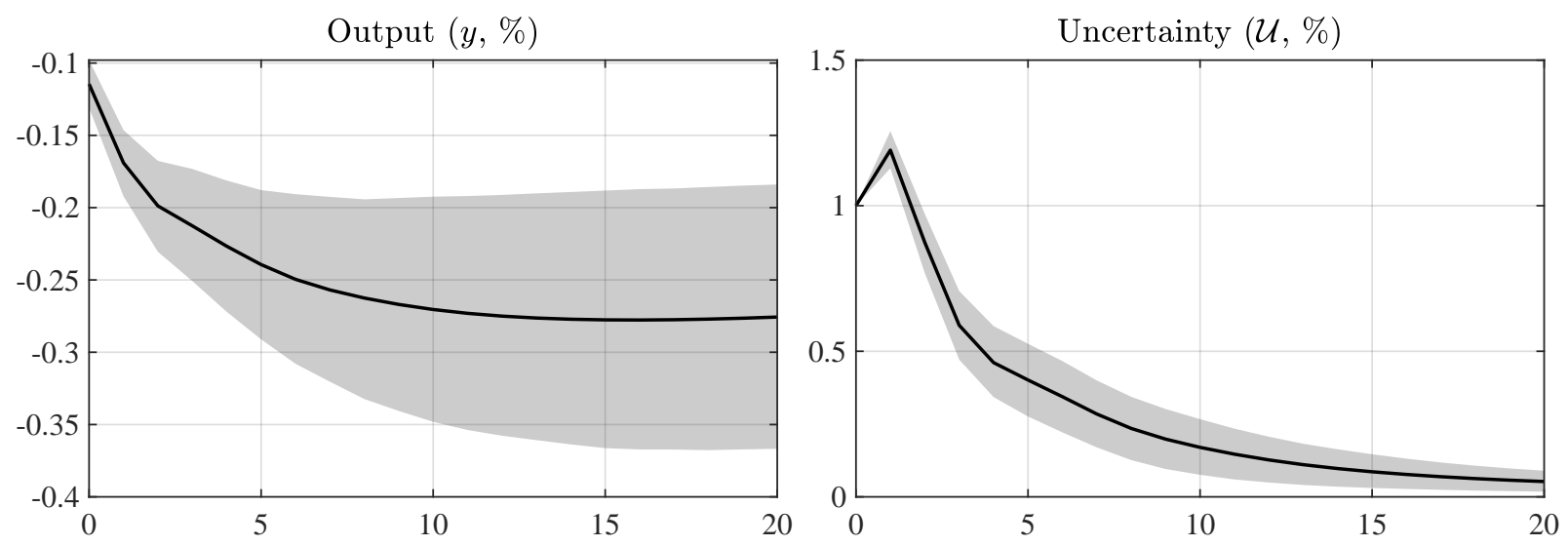

(a) Responses based on actual data. Shaded regions are $68 \%$ confidence intervals.
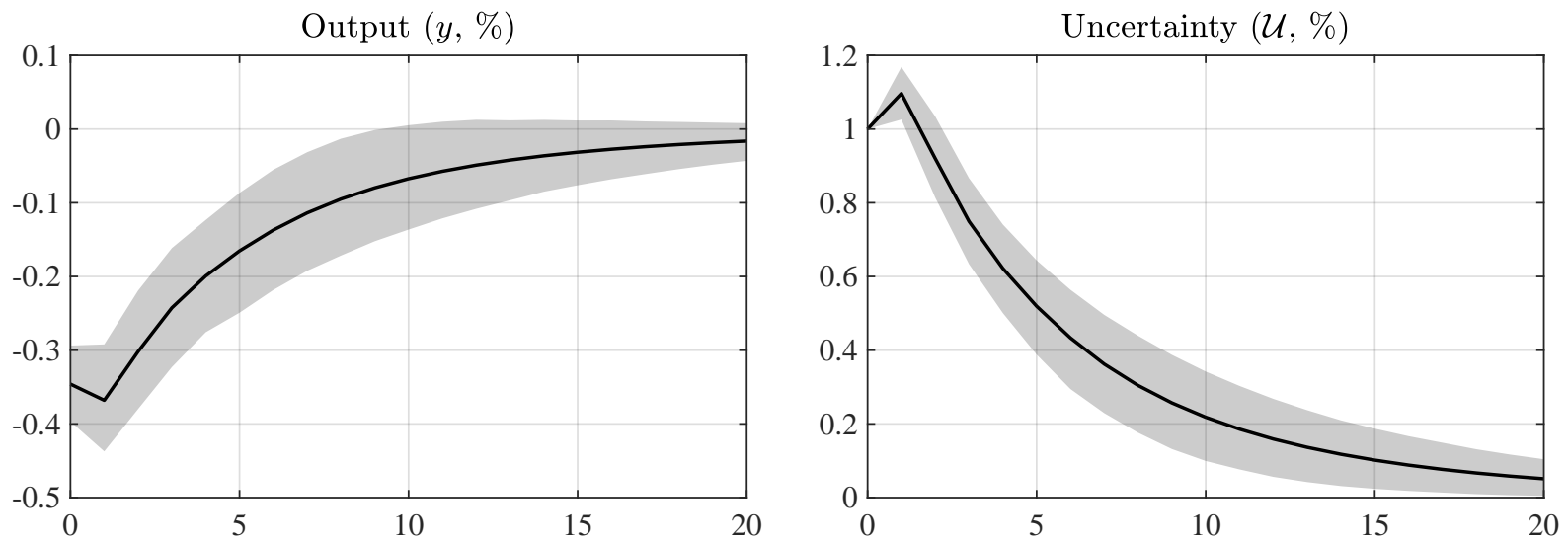

(b) Responses based on simulated data. Shaded regions are $[16 \%, 84 \%]$ credible sets.

Figure 4: Bivariate VAR responses to an uncertainty shock ordered first.

are inconsistent with the data. Consistent with our estimated model, they find the effect of real uncertainty shocks on output is small, while real uncertainty endogenously responds to output shocks.

\section{CONCLUSION}

Aggregate uncertainty displays markedly countercyclical dynamics. This paper uses a battery of calibrated and estimated structural models to shed light on the causal drivers of the negative correlation between uncertainty and output. We find the transmission of uncertainty shocks to output is weak, while uncertainty responds endogenously to first moment shocks in the presence of labor market search frictions. This means countercyclical movements in uncertainty are endogenous responses to fluctuations in real activity, and exogenous uncertainty shocks play virtually no role in driving the business cycle. We focused exclusively on real uncertainty. Extending our analysis to financial uncertainty and its relationship with real activity is an important area for future research. 


\section{REFERENCES}

Andolfatto, D. (1996): "Business Cycles and Labor-Market Search,” American Economic Review, 86, 112-132.

Arellano, C., Y. Bai, And P. J. Kehoe (2019): "Financial Frictions and Fluctuations in Volatility," Journal of Political Economy, 127, 2049-2103, https://doi.org/10.1086/701792.

Atkinson, T., M. Plante, A. W. Richter, And N. A. Throckmorton (2021):

"Complementarity and Macroeconomic Uncertainty," Review of Economic Dynamics, forthcoming, https://doi.org/10.1016/j.red.2021.03.003.

BACHMANN, R. AND C. BAYER (2013): “'Wait-and-See’ Business Cycles?” Journal of Monetary Economics, 60, 704-719, https://doi.org/10.1016/j.jmoneco.2013.05.005.

BAKer, S. R., N. BloOM, AND S. J. DAVIS (2016): "Measuring Economic Policy Uncertainty," Quarterly Journal of Economics, 131, 15931636, https://doi.org/10.1093/qje/qjw024.

BARnichon, R. (2010): “Building a Composite Help-Wanted Index,” Economics Letters, 109, 175-178, https://doi.org/10.1016/j.econlet.2010.08.029.

BASU, S. AND B. BUNDICK (2017): "Uncertainty Shocks in a Model of Effective Demand," Econometrica, 85, 937-958, https://doi.org/10.3982/ECTA13960.

BENHABIB, J., X. LiU, AND P. WANG (2016): "Endogenous Information Acquisition and Countercyclical Uncertainty," Journal of Economic Theory, 165, 601-642, https://doi.org/10.1016/j.jet.2016.07.007.

Bernstein, J., A. W. Richter, And N. A. Throckmorton (2021): "Nonlinear Search and Matching Explained," Federal Reserve Bank of Dallas Working Paper 2106, https://doi.org/10.24149/wp2106.

Blanchard, O. And J. Galí (2010): "Labor Markets and Monetary Policy: A New Keynesian Model with Unemployment," American Economic Journal: Macroeconomics, 2, 1-30, https://doi.org/10.1257/mac.2.2.1.

Bloom, N. (2007): "Uncertainty and the Dynamics of R\&D," American Economic Review, 97, 250-255, https://doi.org/10.1257/aer.97.2.250.

Bloom, N., M. Floetotto, N. Jaimovich, I. S Aporta-Eksten, and S. J. Terry (2018):

“Really Uncertain Business Cycles," Econometrica, 86, 1031-1065, https://doi.org/10.3982/ECTA10927.

Born, B. AND J. PfeIfER (2014): “Policy Risk and the Business Cycle," Journal of Monetary Economics, 68, 68-85, https://doi.org/10.1016/j.jmoneco.2014.07.012. (2021): "Uncertainty Driven Business Cycles: Assessing the Markup Channel,"

Quantitative Economics, 12, 587-623, https://doi.org/10.3982/QE1297.

Brunnermeier, M. K. And Y. SAnnikov (2014): "A Macroeconomic Model with a Financial Sector," American Economic Review, 104, 379-421, https://doi.org/10.1257/aer.104.2.379. 
Cacciatore, M. And F. Ravenna (2021): "Uncertainty, Wages, and the Business Cycle," Economic Journal, forthcoming, https://doi.org/10.1093/ej/ueab019.

Chetty, R., A. Guren, D. Manoli, And A. Weber (2012): "Does Indivisible Labor

Explain the Difference between Micro and Macro Elasticities? A Meta-Analysis of Extensive

Margin Elasticities," in NBER Macroeconomics Annual 2012, Volume 27, ed. by D. Acemoglu,

J. Parker, and M. Woodford, MIT Press, Cambridge, 1-56.

Christiano, L. J., R. Motto, And M. Rostagno (2014): "Risk Shocks," American

Economic Review, 104, 27-65, https://doi.org/10.1257/aer.104.1.27.

Chugh, S. K. (2016): "Firm Risk and Leverage Based Business Cycles," Review of Economic

Dynamics, 20, 111-131, https://doi.org/10.1016/j.red.2016.02.001.

Coleman, II, W. J. (1991): "Equilibrium in a Production Economy with an Income Tax,"

Econometrica, 59, 1091-1104, https://doi.org/10.2307/2938175.

Den HaAn, W., L. B. Freund, And P. Rendahl (2020): "Volatile Hiring: Uncertainty in

Search and Matching Models," Cambridge Working Papers in Economics 20125.

Den HaAn, W. J., G. RAMEY, AND J. WATSON (2000): “Job Destruction and Propagation of

Shocks," American Economic Review, 90, 482-498, https://doi.org/10.1257/aer.90.3.482.

Elsby, M. W. L., G. Solon, And R. Michaels (2009): “The Ins and Outs of Cyclical

Unemployment," American Economic Journal: Macroeconomics, 1, 84-110,

https://doi.org/10.1257/mac.1.1.84.

Fajgelbaum, P., M. Taschereau-Dumouchel, and E. SchaAl (2017): "Uncertainty

Traps," The Quarterly Journal of Economics, 132, 1641-1692,

https://doi.org/10.1093/qje/qjx02.

FERnÁndeZ-VillaVErde, J. AND P. GuERrón-Quintana (2020): “Uncertainty Shocks and

Business Cycle Research,' Review of Economic Dynamics, 37, S118-S146,

10.1016/j.red.2020.06.005.

Fernández-Villaverde, J., P. Guerrón-Quintana, K. Kuester, and J. F.

RUBIO-RAMÍREZ (2015): "Fiscal Volatility Shocks and Economic Activity," American

Economic Review, 105, 3352-84, https://doi.org/10.1257/aer.20121236.

Fernández-Villaverde, J., P. Guerrón-Quintana, J. F. Rubio-RAmírez, And

M. URIBE (2011): "Risk Matters: The Real Effects of Volatility Shocks," American Economic

Review, 101, 2530-61, https://doi.org/10.1257/aer.101.6.2530.

Garcia, C. B. And W. I. Zangwill (1981): Pathways to Solutions, Fixed Points and

Equilibria, Prentice-Hall series in computational mathematics, Prentice-Hall.

GILCHRIST, S., J. W. SiM, AND E. ZAKRAJŠEK (2014): “Uncertainty, Financial Frictions, and

Investment Dynamics,” NBER Working Paper 20038, https://doi.org/10.3386/w20038.

Hagedorn, M. And I. MAnOvsKiI (2008): “The Cyclical Behavior of Equilibrium

Unemployment and Vacancies Revisited," American Economic Review, 98, 1692-1706,

https://doi.org/10.1257/aer.98.4.1692. 
HALL, R. E. (2005): “Employment Fluctuations with Equilibrium Wage Stickiness," American Economic Review, 95, 50-65, https://doi.org/10.1257/0002828053828482.

Hamilton, J. D. (2018): "Why You Should Never Use the Hodrick-Prescott Filter," Review of Economics and Statistics, 100, 831-843, https://doi.org/10.1162/rest_a_00706.

Hodrick, R. J. (2020): “An Exploration of Trend-Cycle Decomposition Methodologies in Simulated Data,” NBER Working Paper 26750, https://doi.org/10.3386/w26750.

Ilut, C., M. Kehrig, And M. Schneider (2018): "Slow to Hire, Quick to Fire: Employment Dynamics with Asymmetric Responses to News," Journal of Political Economy, 126, 2011-2071, https://doi.org/10.1086/699189.

IsAKIN, M. AND P. V. NGO (2020): "Variance Decomposition Analysis for Nonlinear Economic Models," Oxford Bulletin of Economics and Statistics, 82, 1362-1374, https://doi.org/10.1111/obes.12369.

Jermann, U. J. (1998): “Asset Pricing in Production Economies,” Journal of Monetary Economics, 41, 257-275, https://doi.org/10.1016/S0304-3932(97)00078-0.

Jurado, K., S. C. Ludvigson, And S. NG (2015): "Measuring Uncertainty," American Economic Review, 105, 1177-1216, https://www.doi.org/10.1257/aer.20131193.

Justiniano, A. And G. E. PRimiceri (2008): “The Time-Varying Volatility of Macroeconomic Fluctuations," American Economic Review, 98, 604-41, https://www.doi.org/10.1257/aer.98.3.604.

Koop, G., M. H. Pesaran, And S. M. Potter (1996): "Impulse Response Analysis in Nonlinear Multivariate Models," Journal of Econometrics, 74, 119-147, https://doi.org/10.1016/0304-4076(95)01753-4.

Kopecky, K. And R. Suen (2010): "Finite State Markov-Chain Approximations to Highly Persistent Processes," Review of Economic Dynamics, 13, 701-714, https://doi.org/10.1016/j.red.2010.02.002.

LANNE, M. AND H. NyBERG (2016): “Generalized Forecast Error Variance Decomposition for Linear and Nonlinear Multivariate Models," Oxford Bulletin of Economics and Statistics, 78, 595-603, https://doi.org/10.1111/obes.12125.

LEDUC, S. AND Z. LiU (2016): “Uncertainty Shocks are Aggregate Demand Shocks," Journal of Monetary Economics, 82, 20-35, https://doi.org/10.1016/j.jmoneco.2016.07.002.

LJUngQVist, L. And T. J. SARGEnt (2017): “The Fundamental Surplus,” American Economic Review, 107, 2630-2665, https://doi.org/10.1257/aer.20150233.

Ludvigson, S. C., S. MA, AND S. NG (2021): "Uncertainty and Business Cycles: Exogenous Impulse or Endogenous Response?" American Economic Journal: Marcoeconomics, forthcoming.

MendozA, E. G. (2010): “Sudden Stops, Financial Crises, and Leverage," American Economic Review, 100, 1941-1966, https://doi.org/10.1257/aer.100.5.1941. 
Merz, M. (1995): “Search in the Labor Market and the Real Business Cycle," Journal of Monetary Economics, 36, 269-300, https://doi.org/10.1016/0304-3932(95)01216-8.

Mortensen, D. And E. NAGYPAL (2007): "More on Unemployment and Vacancy Fluctuations," Review of Economic Dynamics, 10, 327-347, https://doi.org/10.1016/j.red.2007.01.004.

Mumtaz, H. And F. ZanetTi (2013): “The Impact of the Volatility of Monetary Policy Shocks," Journal of Money, Credit and Banking, 45, 535-558, https://doi.org/10.1111/jmcb.12015.

Newey, W. K. And K. D. West (1987): “A Simple, Positive Semi-Definite, Heteroskedasticity and Autocorrelation Consistent Covariance Matrix," Econometrica, 55, 703-708, https://www.doi.org/10.2307/1913610.

OH, J. (2020): “The Propagation of Uncertainty Shocks: Rotemberg versus Calvo," International Economic Review, 61, 1097-1113, https://doi.org/10.1111/iere.12450.

Petrongolo, B. And C. A. Pissarides (2001): "Looking into the Black Box: A Survey of the Matching Function," Journal of Economic Literature, 39, 390-431, https://doi.org/10.1257/jel.39.2.390.

Plante, M., A. W. Richter, And N. A. Throckmorton (2018): “The Zero Lower Bound and Endogenous Uncertainty," Economic Journal, 128, 1730-1757, https://doi.org/10.1111/ecoj.12445.

Richter, A. W., N. A. Throckmorton, And T. B. Walker (2014): “Accuracy, Speed and Robustness of Policy Function Iteration," Computational Economics, 44, 445-476, https://doi.org/10.1007/s10614-013-9399-2.

Rotemberg, J. J. (1982): "Sticky Prices in the United States," Journal of Political Economy, 90, 1187-1211, https://doi.org/10.1086/261117.

Rouwenhorst, K. G. (1995): "Asset Pricing Implications of Equilibrium Business Cycle Models," in Frontiers of Business Cycle Research, ed. by T. F. Cooley, Princeton, NJ: Princeton University Press, 294-330.

Ruge-Murcia, F. (2012): "Estimating Nonlinear DSGE Models by the Simulated Method of Moments: With an Application to Business Cycles," Journal of Economic Dynamics and Control, 36, 914-938, http:https://doi.org/10.1016/j.jedc.2012.01.00.

SAIJO, H. (2017): “The Uncertainty Multiplier and Business Cycles," Journal of Economic Dynamics and Control, 78, 1-25, https://doi.org/10.1016/j.jedc.2017.02.008.

SEDLÁČEK, P. (2020): "Creative Destruction and Uncertainty," Journal of the European Economic Association, 18, 1814-1843, https://doi.org/10.1093/jeea/jvz047.

SHIMER, R. (2005): "The Cyclical Behavior of Equilibrium Unemployment and Vacancies," American Economic Review, 95, 25-49, https://doi.org/10.1257/0002828053828572. 
SIMS, C. A. (2002): “Solving Linear Rational Expectations Models," Computational Economics, 20, 1-20, https://doi.org/10.1023/A:1020517101123.

StRAub, L. AND R. UlbRicht (2015): "Endogenous Uncertainty and Credit Crunches,"

Toulouse School of Economics Working Paper 15-604.

VAn Nieuwerburgh, S. And L. VeldKamp (2006): "Learning Asymmetries in Real

Business Cycles," Journal of Monetary Economics, 53, 753-772,

https://doi.org/10.1016/j.jmoneco.2005.02.003.

\section{A Data Sources ANd Transformations}

We use the following time-series from 1963-2019 provided by Haver Analytics:

1. Civilian Noninstitutional Population: 16 Years \& Over

Not Seasonally Adjusted, Quarterly, Thousands (LN16N@USECON)

2. Gross Domestic Product: Implicit Price Deflator

Seasonally Adjusted, Quarterly, 2012=100 (DGDP@USNA)

3. Gross Domestic Product

Seasonally Adjusted, Quarterly, Billions of Dollars (GDP@USECON)

4. Personal Consumption Expenditures: Nondurable Goods

Seasonally Adjusted, Quarterly, Billions of Dollars (CN@USECON)

5. Personal Consumption Expenditures: Services

Seasonally Adjusted, Quarterly, Billions of Dollars (CS@USECON)

6. Personal Consumption Expenditures: Durable Goods

Seasonally Adjusted, Quarterly, Billions of Dollars (CD@USECON)

7. Private Fixed Investment

Seasonally Adjusted, Quarterly, Billions of Dollars (F@USECON)

8. Output Per Person, Non-farm Business Sector, All Persons, Seasonally Adjusted, Quarterly, 2012=100 (LXNFS @USNA)

9. Labor Share, Non-farm Business Sector, All Persons, Seasonally Adjusted, Quarterly, Percent (LXNFBL@USNA)

10. Unemployed, 16 Years \& Over

Seasonally Adjusted, Monthly, Thousands (LTU@USECON)

11. Civilian Labor Force: 16 yr \& Over

Seasonally Adjusted, Monthly, Thousands (LF@USECON) 


\section{Civilians Unemployed for Less Than 5 Weeks}

Seasonally Adjusted, Monthly, Thousands (LU0@USECON)

13. Job Openings, Job Openings and Labor Turnover Survey, Seasonally Adjusted, Monthly, Thousands (LJJTLA@USECON)

14. Net Stock: Private Fixed Assets, Annual, Billions of Dollars (EPT@CAPSTOCK)

15. Net Stock: Durable Goods, Annual, Billions of Dollars (EDT@CAPSTOCK)

16. Depreciation: Private Fixed Assets, Annual, Billions of Dollars (KPT@CAPSTOCK)

17. Depreciation: Durable Goods, Annual, Billions of Dollars (KDT@CAPSTOCK)

We also used the following data from other sources:

1. Help Wanted Advertising Index (HWI), based on Barnichon (2010) and in units of the labor force. The series corrects for online advertising and is available on the author's website.

2. Real Uncertainty (U), 3-month horizon, based on Ludvigson et al. (2021). The series is available on Ludvigson's website. The monthly series is averaged to a quarterly frequency.

We applied the following transformations to the above data sources:

1. Per Capita Real Output Growth:

$$
\Delta \log Y_{t}=100\left(\log \left(\frac{G D P_{t}}{D G D P_{t} \times L N 16 N_{t}}\right)-\log \left(\frac{G D P_{t-1}}{D G D P_{t-1} \times L N 16 N_{t-1}}\right)\right) .
$$

2. Per Capita Real Consumption Growth:

$$
\Delta \log C_{t}=100\left(\log \left(\frac{C N_{t}+C S_{t}}{D G D P_{t} \times L N 16 N_{t}}\right)-\log \left(\frac{C N_{t-1}+C S_{t-1}}{D G D P_{t-1} \times L N 16 N_{t-1}}\right)\right) .
$$

\section{Per Capita Real Investment Growth:}

$$
\Delta \log I_{t}=100\left(\log \left(\frac{F_{t}+C D_{t}}{D G D P_{t} \times L N 16 N_{t}}\right)-\log \left(\frac{F_{t-1}+C D_{t-1}}{D G D P_{t-1} \times L N 16 N_{t-1}}\right)\right) .
$$

4. Unemployment Rate: $U_{t}=100\left(L T U_{t} / L F_{t}\right)$.

5. Vacancy Rate: $H W I$ from 1963M1-2000M12 and LJJTLA/LF from 2001M1-2019M12.

6. Short-term Unemployed $\left(U^{s}\right)$ : The redesign of the Current Population Survey (CPS) in 1994 reduced $u_{t}^{s}$. To correct for this bias, we follow Elsby et al. (2009) and scale $u_{t}^{s}$ by the time average of the ratio of $u_{t}^{s} / u_{t}$ for the first and fifth rotations groups to $u_{t}^{s} / u_{t}$ across all rotation groups. Using IPUMS-CPS data, we extract EMPSTAT ("Employment Status"), DURUNEMP ("Continuous weeks unemployed") and MISH ("Month in sample, household level”). Unemployed persons have EMPSTAT equal to 20, 21, or 22. Short-term unemployed 
are persons who are unemployed and have DURUNEMP equal to 4 or less. Incoming rotation groups have MISH equal to 1 or 5 . Using the final weights, WTFINL, we calculate unemployment rates conditional on the appropriate values of MISH and DURUNEMP. We then apply the X-12 seasonal adjustment function in STATA to the time series for the ratio. Finally, we take an average of the seasonally adjusted series from 1994-2019. This process yields an average of 1.1725 , so $U^{s}$ equals $L U 0$ prior to 1994 and $1.1725 \times L U 0$ after 1994 .

7. Job-Finding Rate: $f_{t}=1-\left(L T U_{t}-U_{t}^{s}\right) / L T U_{t-1}$.

8. Job Separation Rate: $s_{t}=1-\exp \left(-\tilde{s}_{t}\right)$, where $\tilde{s}_{t}$ satisfies

$$
L T U_{t+1}=\frac{\left(1-\exp \left(-\tilde{f}_{t}-\tilde{s}_{t}\right)\right) \tilde{s}_{t} L F_{t}}{\tilde{f}_{t}+\tilde{s}_{t}}+\exp \left(-\tilde{f}_{t}-\tilde{s}_{t}\right) L T U_{t}, \quad \tilde{f}_{t}=-\log \left(1-f_{t}\right) .
$$

9. Real Wage: $w_{t}=L X N F B L_{t} \times L X N F S_{t}$.

10. Wage Elasticity: Slope coefficient from regressing $w_{t}$ on an intercept and $L X N F S_{t}$.

11. Depreciation Rate: $\delta=\left(1+\frac{1}{T / 12} \sum_{t=1}^{T / 12}\left(K P T_{t}+K D T_{t}\right) /\left(E P T_{t-1}+E D T_{t-1}\right)\right)^{1 / p}-1$, where $T=684$ is the number of months in our balanced sample and $p$ is the number of periods per year in a given model (RBC and NK models, $p=4$; DMP model, $p=12$ ).

12. Capital Share of Income: $\alpha=1-\frac{1}{T / 3} \sum_{t=1}^{T / 3} L X N F B L$.

13. Inflation Rate: $\pi_{t}=1+\log \left(D G D P_{t} / D G D P_{t-1}\right)$.

All monthly time series are averaged to a quarterly frequency. The data is detrended using a Hamilton filter with an 8 quarter window. All empirical targets are computed using quarterly data.

\section{B Solution Method}

The equilibrium system of a model is summarized by $E\left[g\left(\mathbf{x}_{t+1}, \mathbf{x}_{t}, \varepsilon_{t+1}\right) \mid \mathbf{z}_{t}, \vartheta\right]=0$, where $g$ is a vector-valued function, $\mathbf{x}_{t}$ is a vector of variables, $\varepsilon_{t}$ is a vector of shocks, $\mathbf{z}_{t}$ is a vector of states, and $\vartheta$ is a vector of parameters. There are many ways to discretize the TFP level shock and volatility process. We use the Markov chain in Rouwenhorst (1995), which Kopecky and Suen (2010) show outperforms other methods for approximating autoregressive processes. For our estimated model, the bounds on $a_{t}$ and $k_{t-1}$ are set to $\pm 8 \%$ of their deterministic steady states, while $n_{t-1}$ ranges from 0.88 to 0.98 . These bounds ensure that simulations contain at least $99 \%$ of the ergodic distribution. We specify 7 states for $\sigma_{a, t}, 11$ states for $\varepsilon_{a, t+1}$, and discretize $a_{t}, k_{t-1}$, and $n_{t-1}$ into 11,7 , and 7 evenly-spaced points, respectively. The product of the points in each dimension, $D$, is the total nodes in the state space ( $D=3,773$ ). The realization of $\mathbf{z}_{t}$ on node $d$ is denoted $\mathbf{z}_{t}(d)$. The Rouwenhorst method provides integration nodes, $\left[\varepsilon_{a, t+1}(m), \sigma_{a, t+1}(m)\right]$, with weights, $\phi(m)$, for $m \in\{1, \ldots, M\}$. The realizations of $\sigma_{a, t+1}$ are the same as $\sigma_{a, t}$ because it is a Markov chain. 
Since vacancies $v_{t} \geq 0$, we introduce an auxiliary variable, $\mu_{t}$, such that $v_{t}=\max \left\{0, \mu_{t}\right\}^{2}$ and $\lambda_{t}=\max \left\{0,-\mu_{t}\right\}^{2}$, where $\lambda_{t}$ is the Lagrange multiplier on the non-negativity constraint. If $\mu_{t} \geq 0$, then $v_{t}=\mu_{t}^{2}$ and $\lambda_{t}=0$. When $\mu_{t}<0$, the constraint is binding, $v_{t}=0$, and $\lambda_{t}=\mu_{t}^{2}$. Therefore, the constraint on $v_{t}$ is transformed into a pair of equalities (Garcia and Zangwill, 1981).

The vector of policy functions and the realization on node $d$ are denoted by $\mathbf{p} \mathbf{f}_{t}$ and $\mathbf{p} \mathbf{f}_{t}(d)$, where $\mathbf{p} \mathbf{f}_{t} \equiv\left[\mu_{v, t}\left(\mathbf{z}_{t}\right), c_{t}\left(\mathbf{z}_{t}\right)\right]$. The following steps outline our policy function iteration algorithm:

1. Use Sims's (2002) gensys algorithm to solve the log-linear model. Then map the solution for the policy functions to the discretized state space. This provides an initial conjecture.

2. On iteration $j \in\{1,2, \ldots\}$ and each node $d \in\{1, \ldots, D\}$, use Chris Sims's csolve to find $\mathbf{p f}_{t}(d)$ to satisfy $E\left[g(\cdot) \mid \mathbf{z}_{t}(d), \vartheta\right] \approx 0$. Guess $\mathbf{p f}_{t}(d)=\mathbf{p} \mathbf{f}_{j-1}(d)$. Then apply the following:

(a) Solve for all variables dated at time $t$, given $\mathbf{p} \mathbf{f}_{t}(d)$ and $\mathbf{z}_{t}(d)$.

(b) Linearly interpolate the policy functions, $\mathbf{p f}_{j-1}$, at the updated state variables, $\mathbf{z}_{t+1}(m)$, to obtain $\mathbf{p} \mathbf{f}_{t+1}(m)$ on every integration node, $m \in\{1, \ldots, M\}$.

(c) Given $\left\{\mathbf{p} \mathbf{f}_{t+1}(m)\right\}_{m=1}^{M}$, solve for the other elements of $\mathbf{s}_{t+1}(m)$ and compute

$$
E\left[g\left(\mathbf{x}_{t+1}, \mathbf{x}_{t}(d), \varepsilon_{t+1}\right) \mid \mathbf{z}_{t}(d), \vartheta\right] \approx \sum_{m=1}^{M} \phi(m) g\left(\mathbf{x}_{t+1}(m), \mathbf{x}_{t}(d), \varepsilon_{t+1}(m)\right) .
$$

When csolve converges, set $\mathbf{p f}_{j}(d)=\mathbf{p f}_{t}(d)$.

3. Repeat step 2 until maxdist m $_{j}<10^{-6}$, where $\operatorname{maxdist}{ }_{j} \equiv \max \left\{\left|\mathbf{p f _ { j }}-\mathbf{p f}_{j-1}\right|\right\}$. When that criterion is satisfied, the algorithm has converged to an approximate nonlinear solution.

The algorithm is programmed in Fortran with Open MPI and run on the BigTex supercomputer.

\section{Estimation Method}

The estimation procedure has two stages. The first stage estimates moments in the data using a 2step Generalized Method of Moments (GMM) estimator with a Newey and West (1987) weighting matrix with 5 lags. The second stage is a Simulated Method of Moments (SMM) procedure that searches for a parameter vector that minimizes the distance between the GMM estimates in the data and short-sample predictions of the model, weighted by the diagonal of the GMM estimate of the variance-covariance matrix. The second stage is repeated for many different draws of shocks to obtain standard errors for the parameter estimates. The following steps outline the algorithm:

1. Use GMM to estimate the targets, $\hat{\Psi}_{T}^{D}$, and the diagonal of the covariance matrix, $\hat{\Sigma}_{T}^{D}$.

2. Use SMM to estimate the nonlinear DMP model. Given a random seed, $h$, draw a $B+T$ period sequence for each shock in the model, where $B=1,000$ is a burn-in period and $T=$ 687 is the length of the monthly time series. Denote the shock matrix by $\mathcal{E}^{s}=\left[\varepsilon_{a}^{s}, \varepsilon_{s v}^{s}\right]_{t=1}^{B+T}$ ). 
For shock sequence $s \in\left\{1, \ldots, N_{s}\right\}$, run the following steps:

(a) Evaluate the loss function for $i \in\left\{1, \ldots, N_{m}\right\}$ random draws in the parameter space.

i. Draw $\hat{\theta}_{i}$ from a multivariate normal distribution centered at a user-specified mean parameter vector, $\bar{\theta}$, with diagonal covariance matrix, $\Sigma_{0}$.

ii. Solve the model using the algorithm in Appendix B given $\hat{\theta}_{i}$. Return to step $\mathrm{i}$ if the linear solution does not exist or the nonlinear algorithm does not converge.

iii. Given $\mathcal{E}^{s}(r)$, simulate the model $R$ times for $B+T$ periods. We draw initial states from the ergodic distribution by burning off the first $B$ periods and aggregate to a quarterly frequency. For each repetition $r$, calculate the moments $\Psi_{T}^{M}\left(\hat{\theta}_{i}, \mathcal{E}^{s}(r)\right)$.

iv. Calculate the mean moments across the $R$ simulations,

$$
\bar{\Psi}_{R, T}^{M}\left(\hat{\theta}_{i}, \mathcal{E}^{s}\right)=\frac{1}{R} \sum_{r=1}^{R} \Psi_{T}^{M}\left(\hat{\theta}_{i}, \mathcal{E}^{s}(r)\right)
$$

and evaluate the loss function:

$$
J_{i}=\left[\hat{\Psi}_{T}^{D}-\bar{\Psi}_{R, T}^{M}\left(\hat{\theta}_{i}, \mathcal{E}^{s}\right)\right]^{\prime}\left[\hat{\Sigma}_{T}^{D}(1+1 / R)\right]^{-1}\left[\hat{\Psi}_{T}^{D}-\bar{\Psi}_{R, T}^{M}\left(\hat{\theta}_{i}, \mathcal{E}^{s}\right)\right]
$$

(b) Find a guess, $\hat{\theta}_{0}$, for the $N_{p}$ estimated parameters and the covariance matrix, $\Sigma_{0}$ :

i. Find the parameter draw $\hat{\theta}_{0}$ that corresponds to $\min \left\{J_{i}\right\}_{i=1}^{N_{m}}$.

ii. Find all $J_{i}$ below the median, stack the corresponding draws in a $N_{m} / 2 \times N_{p}$ matrix, $\hat{\Theta}$, and define the $(i, j)$ element as $\tilde{\Theta}_{i, j}=\hat{\Theta}_{i, j}-\sum_{i=1}^{N_{m} / 2} \hat{\Theta}_{i, j} /\left(N_{m} / 2\right)$.

iii. Calculate $\Sigma_{0}=\tilde{\Theta}^{\prime} \tilde{\Theta} /\left(N_{m} / 2\right)$.

(c) Minimize $J$ with simulated annealing. For $i \in\left\{0, \ldots, N_{d}\right\}$, repeat the following steps:

i. Draw a candidate vector of parameters, $\hat{\theta}_{i}^{\text {cand }}$, where

$$
\hat{\theta}_{i}^{\text {cand }} \sim \begin{cases}\hat{\theta}_{0} & \text { for } i=0, \\ \mathbb{N}\left(\hat{\theta}_{i-1}, c_{0} \Sigma_{0}\right) & \text { for } i>0 .\end{cases}
$$

We set $c_{0}$ to target an average acceptance rate of $50 \%$ across seeds.

ii. Repeat steps 2a, ii-iv.

iii. Accept or reject the candidate draw according to

$$
\left(\hat{\theta}_{i}, J_{i}\right)= \begin{cases}\left(\hat{\theta}_{i}^{\text {cand }}, J_{i}^{\text {cand }}\right) & \text { if } i=0 \\ \left(\hat{\theta}_{i}^{\text {cand }}, J_{i}^{\text {cand }}\right) & \text { if } \min \left(1, \exp \left(J_{i-1}-J_{i}^{\text {cand }}\right) / c_{1}\right)>\hat{u} \\ \left(\hat{\theta}_{i-1}, J_{i-1}\right) & \text { otherwise }\end{cases}
$$

where $c_{1}$ is the temperature and $\hat{u}$ is a draw from a uniform distribution. 
(d) Find $\hat{\theta}_{0}^{u p}$ and $\Sigma_{0}^{u p}$ following step $2 \mathrm{~b}$.

(e) Repeat steps 2c-d $N_{S M M}$ times, initializing at $\hat{\theta}_{0}=\hat{\theta}_{0}^{u p}$ and $\Sigma_{0}=\Sigma_{0}^{u p}$. Gradually decrease the temperature. Across all $N_{S M M}$ stages, find the lowest $J$ value, denoted $J_{\text {guess }}$, and the corresponding draw, $\theta_{\text {guess }}$.

(f) Minimize the same loss function with MATLAB's fminsearch starting at $\theta_{\text {guess }}$. The minimum is $\hat{\theta}_{\min }$ with a loss function value of $J_{\min }$. Repeat, each time updating the guess, until $J_{\text {guess }}-J_{\min }<0.001$. The parameter estimates correspond to $J_{\min }$.

The set of SMM parameter estimates $\left\{\hat{\theta}^{s}\right\}_{s=1}^{N_{s}}$ approximate the joint sampling distribution of the parameters. We report the mean, $\bar{\theta}=\sum_{s=1}^{N_{s}} \hat{\theta}^{s} / N_{s}$, and standard errors. The reported moments are based on the mean parameter estimates, $\bar{\Psi}_{T}^{M}=\bar{\Psi}_{R, T}^{M}(\bar{\theta}, \mathcal{E})$.

We set $N_{s}=200, R=1,000, N_{S M M}=3, N_{m}=1,000, N_{d}=500$, and $N_{p}=10$. For each simulated annealing stage, $c_{0}$ is $0.1,0.7$, and 1.0 , and $c_{1}$ is $1.0,0.5$, and 0.25 , respectively. The algorithm was programmed in Fortran and executed with Open MPI on the BigTex supercomputer.

\section{Model CALibrations}

\begin{tabular}{lcccc}
\hline & RBC & NK & DMP & Calibration Target \\
\hline Discount Factor $(\beta)$ & 0.995 & 0.995 & 0.9983 & $2 \%$ Annual Real Interest Rate \\
Cost Share of Capital $(\alpha)$ & 0.3888 & 0.3888 & 0.3888 & Sample Mean \\
Capital Depreciation Rate $(\delta)$ & 0.0238 & 0.0238 & 0.0079 & Sample Mean \\
Frisch Elasticity $(1 / \gamma)$ & 0.5 & 0.5 & - & Chetty et al. (2012) \\
Elasticity of Substitution $(\theta)$ & - & 11 & - & $10 \%$ Price Markup \\
Monetary Response to Inflation $\left(\phi_{\pi}\right)$ & - & 1.5 & - & Leduc and Liu (2016) \\
Price Adjustment Costs $(\varphi)$ & - & 118.2 & - & Leduc and Liu (2016) \\
Outside Option $(b)$ & - & - & 0.955 & Hagedorn and Manovskii (2008) \\
Bargaining Weight $(\eta)$ & - & - & 0.052 & Hagedorn and Manovskii (2008) \\
Matching Elasticity $(\phi)$ & - & - & 0.5 & Leduc and Liu (2016) \\
Level Shock Persistence $\left(\rho_{a}\right)$ & 0.85 & 0.85 & 0.95 & Sample Autocorrelation \\
Volatility Shock Persistence $\left(\rho_{s v}\right)$ & 0.75 & 0.75 & 0.8667 & Leduc and Liu (2016) \\
Steady-State Hours $(\bar{n})$ & 0.33 & 0.33 & - & Standard Value \\
Steady-State Inflation Rate $(\bar{\pi})$ & - & 1.0083 & - & Sample Mean \\
Steady-State Unemployment Rate $(\bar{u})$ & - & - & 0.0597 & Sample Mean \\
Steady-State Job Separation Rate $(\bar{s})$ & - & - & 0.0328 & Sample Mean \\
Steady-State Job Finding Rate $(\bar{f})$ & - & - & 0.4188 & Sample Mean \\
Steady-State Job Filling Rate $(\bar{q})$ & - & - & 0.3306 & Leduc and Liu (2016) \\
\hline
\end{tabular}

Table 7: Calibrated parameters. The RBC and NK models are quarterly and the DMP model is monthly. 


\section{E VAR ROBUSTNESS}
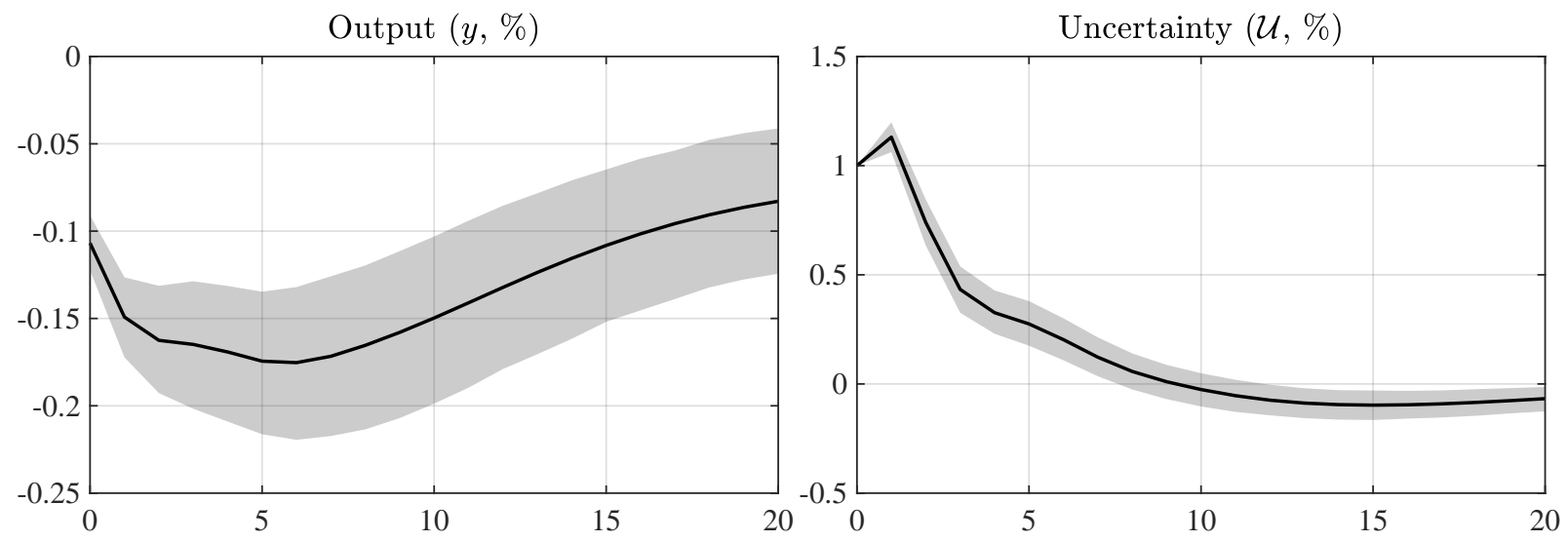

(a) Responses based on actual data. Shaded regions are $68 \%$ confidence intervals.
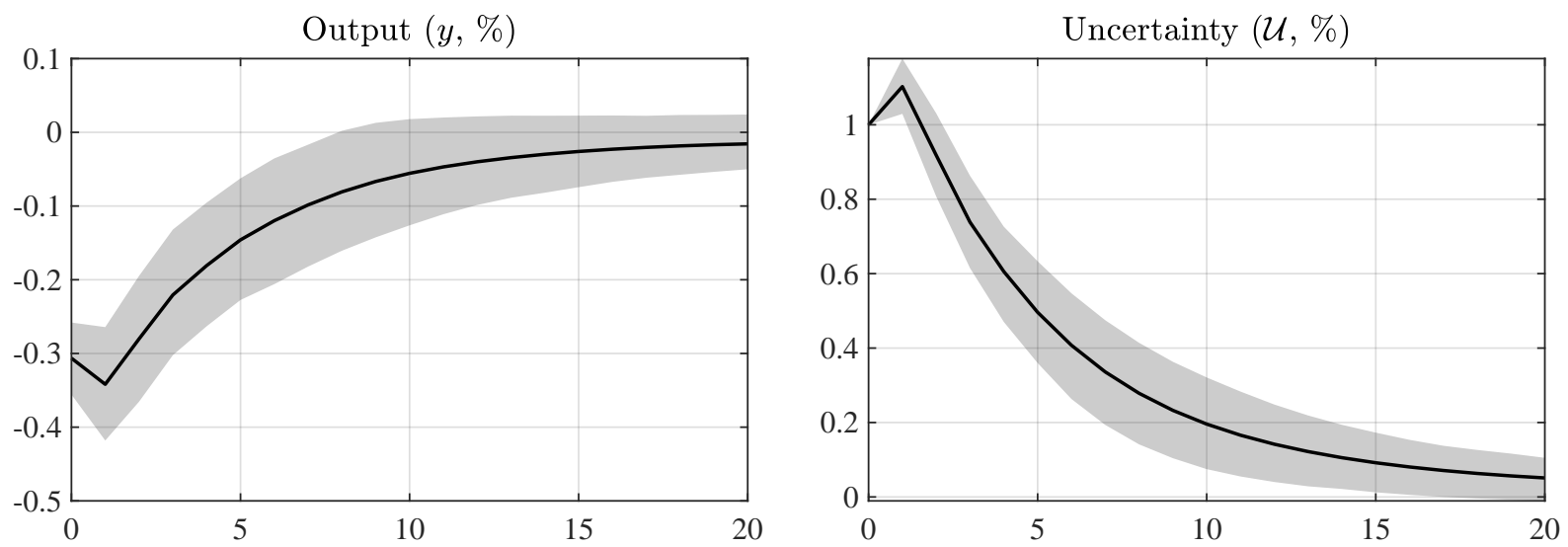

(b) Responses based on simulated data. Shaded regions are $[16,84 \%]$ credible sets.

Figure 5: VAR responses to an uncertainty shock where $Y_{t}=[\mathcal{U}, y, c, i, u]$. 